\title{
COMPARATIVE ANALYSES OF THE THERMAL PERFORMANCE OF REFRIGERANTS R134A, R245fa, R407C AND R600a DURING FLOW BOILING IN A MICROCHANNELS HEAT SINK
}

\author{
H. L. S. L. Leão ${ }^{a, b}$, \\ D. B. Marchetto ${ }^{a}$, \\ and G. Ribatski ${ }^{\text {a }}$ \\ ABSTRACT \\ A comparative study of the performance of of refrigerants R134a, R407C, \\ R245fa and R600a during flow boiling was performed for a $123 \times 494 \mu \mathrm{m}^{2}$ \\ heat sink composed of 50 parallel rectangular microchannels. Heat transfer \\ experimental results for heat fluxes up to $310 \mathrm{~kW} / \mathrm{m}^{2}$, mass velocities from \\ 300 to $800 \mathrm{~kg} /\left(\mathrm{m}^{2} \mathrm{~s}\right)$, liquid subcoolings of 5 and $10{ }^{\circ} \mathrm{C}$ and saturation \\ temperature close to $30^{\circ} \mathrm{C}$ were obtained. Global heat transfer coefficients \\ (footprint) up to $10 \mathrm{~kW} /\left(\mathrm{m}^{2}{ }^{\circ} \mathrm{C}\right)$ were found. The liquid superheating \\ necessary for the onset of nucleate boiling (ONB) was also characterized, \\ and the fluids R245fa and R407C presented the highest and lowest, \\ respectively, superheating to trigger the boiling process. Moreover, for a \\ fixed averaged vapor quality, the average effective heat transfer coefficient \\ increases with increasing mass velocity and liquid subcooling. The \\ refrigerants R600a and R407C presented the highest and the lowest heat \\ transfer coefficients, respectively. Five heat transfer predictive methods \\ from literature provided accurate predictions of the data for R134a, R245fa \\ and R600a, capturing most of the data trends. No one method provided \\ accurate predictions of the heat transfer coefficient data of R407C. \\ Received: April 16, 2018 \\ Revised: June 04, 2018 \\ Accepted: October 18, 2018 \\ Keywords: flow boiling; heat transfer coefficient; microchannels heat sink

\section{NOMENCLATURE} \\ G mass velocity, $\mathrm{kg} /\left(\mathrm{m}^{2} . \mathrm{s}\right)$ \\ $\mathrm{H}$ microchannel depth, $\mathrm{m}$ \\ $\overline{\mathrm{h}}$ average heat transfer coefficient, $\mathrm{W} /\left(\mathrm{m}^{2}{ }^{\circ} \mathrm{C}\right)$ \\ i enthalpy, $\mathrm{J} / \mathrm{kg}$ \\ $\mathrm{k}$ thermal conductivity, $\mathrm{W} /\left(\mathrm{m} .{ }^{\circ} \mathrm{C}\right)$ \\ $\mathrm{L}$ microchannel length, $\mathrm{m}$ \\ $\overline{\mathrm{m}} \quad$ mass flux, $\mathrm{kg} / \mathrm{s}$ \\ $\mathrm{p}$ absolute pressure, $\mathrm{kPa}$ \\ Q dissipated energy, W \\ $\mathrm{q}^{\prime \prime}$ heat flux, $\mathrm{W} / \mathrm{m}^{2}$ \\ T temperature, ${ }^{\circ} \mathrm{C}$ \\ $\overline{\mathrm{T}}$ average temperature, ${ }^{\circ} \mathrm{C}$ \\ W microchannel width, $\mathrm{m}$ \\ $\overline{\mathrm{x}} \quad$ average vapor quality, dimensionless

\section{Greek symbols} \\ $\xi \quad$ fraction of data predicted within an error band \\ of $\pm 30 \%, \%$ \\ $\Delta \mathrm{p} \quad$ differential pressure, $\mathrm{kPa}$ \\ $\Delta \overline{\mathrm{T}} \quad$ temperature difference, ${ }^{\circ} \mathrm{C}$ \\ $\Delta \mathrm{T}_{\text {sub }}$ liquid subcooling, ${ }^{\circ} \mathrm{C}$

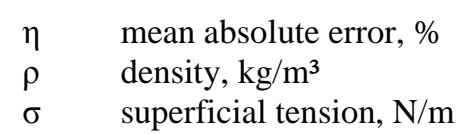

\section{Subscripts} \\ 0 two-phase flow onset along the microchannel \\ $1 \phi \quad$ single-phase \\ calc calculated \\ eff effective, effectively in contact with fluid \\ elet electrical power \\ end end of the single-phase region \\ env environment \\ exp experimental \\ fluid fluid \\ ftp footprint area \\ in heat spreader inlet \\ 1 liquid \\ lv liquid-vapor \\ ONB onset of nucleate boiling \\ out heat spreader outlet \\ plm inlet and outlet plenum \\ real real, energy dissipated by microchannels \\ sat saturate
}


TP two-phase flow

v vapor

wall heat spreader wall

\section{INTRODUCTION}

Over the last decades, the size of electronic devices decreased substantially, as result of the drastic increase of the number of transistors in a microprocessor. However, the progressive miniaturization of microprocessors takes place in conjunction with the increasing of the demand of dissipating heat. In this context, the electronic industry is facing the challenge of removing heat fluxes up to $300 \mathrm{~W} / \mathrm{cm}^{2}$. Moreover, according to Agostini et al. (2007) and do Nascimento et al. (2013), the need of dissipating even higher heat fluxes is expected for a near future. In general, forced-convection of a liquid through microchannels, especially water, is being implemented for replacing air-cooling, as a more efficient solution (Colgan et al., 2007; Saini and Webb, 2003; Tuckerman and Pease, 1981). Besides, heat spreaders based on flow boiling mechanism through microchannels are being also considered as an alternative for thermal management of microprocessors. As advantages over single-phase based cooling, an evaporation process provides higher heat transfer coefficients and an almost isothermal temperature distribution along the surface of the heat spreader. These characteristics favor the compactness of the heat spreader and the improvement of the microprocessor performance. It is important highlighting that the need of dissipating extremely high heat fluxes under conditions of wellconditioned temperatures is also observed in laser diodes, photovoltaic cells, microchemical reactors, solar power concentrators, nuclear power plants, accelerators of particles, medical equipment, lens and mirrors.

According to the broad literature review of Sempértegui-Tapia and Ribatski (2013), the majority of studies concerning flow boiling through heat sinks based on multi- microchannels were performed for parallel channels with rectangular cross sections. Most of these heat sinks were fabricated on silicon and copper, due to the high thermal conductivity of these materials, using micro-manufacturing processes such as micro-machining, deposition process, laser machining and chemical etching. Although being an aspect ignored by several authors, it is important highlight that the manufacturing process is directly connected with the uniformity of the cross section along the length of the channel and its surface roughness. These parameters exercise great influence on the heat spreader performance.

Due to their contribution to ozone layer depletion and greenhouse effect, CFCs, HCFCs and HFCs are being discarded as refrigerant and various alternatives were proposed and evaluated to replace them, as hydrofluoroolefins (HFOs) and natural refrigerants (hydrocarbons, $\mathrm{CO} 2$ and ammonia). As pointed out by Thome (1996) and Chen et al. (2005), despite of some concerns about flammable refrigerants due to safety aspects, propane and isobutene are widely used as refrigerants in applications involving cascade refrigeration systems in ethylene production facilities and domestic refrigerators. In this context, it is important to highlight the almost negligible refrigerant charge contained in a heat spreader developed for electronic cooling, corresponding for the configuration evaluated in the present study to only $0.16 \mathrm{~g}$ considering all the channels filled with liquid and to $0.12 \mathrm{~g}$ under evaporation conditions. However, most of studies on flow boiling through heat spreaders based on multi-microchannels were performed for halocarbon refrigerants and water as pointed out by Chávez et al. (2014). Moreover, according to the present author's knowledge, the performance of hydrocarbons evaporating across heat sinks based on multimicrochannels has reduced results in the literature.

Authors from literature (Agostini and Thome, 2005; Harirchian and Garimella, 2009; VakiliFarahani et al., 2013; Zhang, 2005; Zhang et al., 2005) pointed out that the knowledge of the heat transfer process during flow boiling in a microchannel-based heat spreader is still limited due to a complex combination of heat transfer and twophase flow mechanisms. According to Tibiriçá and Ribatski (2013) and Agostini and Thome (2005), distinct heat transfer trends during flow boiling in microchannels are noted when studies from different laboratories are compared. Additionally, the predominant heat transfer mechanisms during flow boiling inside microchannels are still controversial. Nevertheless, it is well established in literature that for conventional channels the heat transfer process during flow boiling is governed by nucleate boiling and forced convection effects. Based on this aspect and on the behavior of the heat transfer coefficient with varying experimental parameter, authors (KaewOn and Wongwises, 2009; Kaew-On et al., 2011; Kew and Cornwell, 1997) have speculated that nucleate boiling effects is the main heat transfer mechanism during flow boiling in microchannels based heat sinks.

Studies available in the open literature have also highlighted the presence of thermal instabilities that are responsible for a drastic reduction of the overall heat transfer coefficient (Bertsch et al., 2008; Chen and Garimella, 2006; Daniels et al., 2011; Hetsroni et al., 2002; Park and Thome, 2010; Wang et al., 2008; $\mathrm{Xu}$ et al., 2005). These instabilities affect not only the heat transfer coefficient but also enhance the pressure drop and diminish the critical heat flux. Recently, Ribatski (2013) have emphasized that the flow pattern dynamics in multi-microchannels are not the same as in single microchannels. In multimicrochannels configurations, backflows are usually 
present. Therefore, the inlet plenum configuration influences the two-phase flow topology and its dynamics along the channels, affecting, consequently, the heat transfer coefficient, pressure drop and critical heat flux.

Szczukiewicz et al. (2013a, 2013b, 2013c, 2014) observed significant mal-distribution effects of the refrigerant among the channels and its harmful effect to the temperature distribution on the footprint surface of a heat sink based on parallel microchannels. By adding restrictions to the flow at the inlet of each microchannel, Szczukiewicz et al. (2014) equalized the two-phase flow distribution among the channels and minimized thermal instability effects. Analogous to Ribatski (2013), Szczukiewicz et al. (2014) also pointed out that care should be taken when experimental data for microchannels based heat sinks are compared with data and predictive methods for single channels due to differences in the heat transfer and fluid dynamics behaviors.

In this context, the present study presents a comparison of heat transfer performance during flow boiling in a heat spreader based on multi- microchannels for refrigerants R600a R134a, R245fa and R407C. Table 1 compares the thermophysical characteristics of these refrigerants. According to this table, the refrigerant R600a is a medium pressure natural refrigerant that can be considered suitable in order to replace $\mathrm{R} 134 \mathrm{a}$ and $\mathrm{R} 407 \mathrm{C}$. On the other hand, R245fa is a low pressure refrigerant, and, therefore less suitable to leaks concerns. Although R600a is flammable, according to Tab. 1, its charge for the heat spreader evaluated in the present study, besides being small as above mentioned, is at least half of the value of the other refrigerants which are non-flammable. Moreover, the ideal COP of R600a is higher than of R407C and R134a and only slightly lower than of R245fa.

The experimental results described in the present study cover heat fluxes up to $320 \mathrm{~kW} / \mathrm{m}^{2}$ (based on the footprint area) and average saturation temperature referred to the pressure at the microchannels inlet of $31^{\circ} \mathrm{C}$ for R245fa and $26^{\circ} \mathrm{C}$ for R600a R134a, and R407C. The experimental results were carefully analyzed and compared against heat transfer predictive methods from literature.

Table 1. Thermophysical properties (estimated using EES).

\begin{tabular}{|c|c|c|c|c|}
\hline Properties & R407C & R134a & R600a & R245fa \\
\hline Molecular weight $[\mathrm{kg} / \mathrm{mol}]$ & 86.2 & 102 & 58.12 & 134 \\
\hline Critical pressure $[\mathrm{kPa}]$ & 4632 & 4059 & 3640 & 3651 \\
\hline Critical temperature $\left[{ }^{\circ} \mathrm{C}\right]$ & 86.2 & 101 & 134.7 & 154 \\
\hline Liquid saturated pressure to $25^{\circ} \mathrm{C}[\mathrm{kPa}]$ & 1190 & 665.8 & 350.4 & 147.8 \\
\hline Liquid density to $25^{\circ} \mathrm{C}\left[\mathrm{kg} / \mathrm{m}^{3}\right]$ & 1138 & 1207 & 549.9 & 1339 \\
\hline Vapor density to $25^{\circ} \mathrm{C}\left[\mathrm{kg} / \mathrm{m}^{3}\right]$ & 43.72 & 32.37 & 9.123 & 8.525 \\
\hline Liquid viscosity to $25^{\circ} \mathrm{C}\left[10^{3} \mathrm{~kg} /(\mathrm{m} . \mathrm{s})\right]$ & 0.1516 & 0.1944 & 0.15 & 0.4063 \\
\hline Vapor viscosity to $25^{\circ} \mathrm{C}\left[10^{3} \mathrm{~kg} /(\mathrm{m} . \mathrm{s})\right]$ & 0.01261 & 0.01197 & 0.007739 & 0.1015 \\
\hline Liquid Specific Heat to $25^{\circ} \mathrm{C}\left[\mathrm{kJ} /\left(\mathrm{kg} .{ }^{\circ} \mathrm{C}\right)\right]$ & 1.533 & 1.425 & 2.45 & 1.322 \\
\hline Vapor Specific Heat to $25^{\circ} \mathrm{C}\left[\mathrm{kJ} /\left(\mathrm{kg} .{ }^{\circ} \mathrm{C}\right)\right]$ & 1.133 & 1.032 & 1.819 & 0.9538 \\
\hline Enthalpy of vaporization to $25^{\circ} \mathrm{C}[\mathrm{kJ} / \mathrm{kg}]$ & 183.4 & 177.8 & 329.1 & 190.3 \\
\hline Liquid thermal conductivity to $25^{\circ} \mathrm{C}\left[\mathrm{W} /\left(\mathrm{m} .{ }^{\circ} \mathrm{C}\right)\right]$ & 0.0843 & 0.08323 & 0.08894 & 0.08115 \\
\hline Vapor thermal conductivity to $25^{\circ} \mathrm{C}\left[\mathrm{W} /\left(\mathrm{m} .{ }^{\circ} \mathrm{C}\right)\right]$ & 0.01442 & 0.01456 & 0.01694 & 0.01395 \\
\hline Superficial Tension $[\mathrm{N} / \mathrm{m}]$ & 0.006892 & 0.008028 & 0.009857 & 0.01363 \\
\hline Heat sink refrigerant inventory for liquid $[\mathrm{mg}]^{*}$ & 340.1 & 359.6 & 163.2 & 396.8 \\
\hline Heat sink refrigerant inventory for vapor $[\mathrm{mg}]^{*}$ & 11 & 8.16 & 2.3 & 2.1 \\
\hline $\begin{array}{l}\text { Heat sink refrigerant inventory for liquid-vapor } \\
{[\mathrm{mg}]^{* *}}\end{array}$ & 269.6 & 281.8 & 126.7 & 299.8 \\
\hline Inflamability & $\begin{array}{l}\text { Non- } \\
\text { flammable } \\
\text { gas }\end{array}$ & $\begin{array}{c}\text { Non- } \\
\text { flammable } \\
\text { gas }\end{array}$ & $\begin{array}{c}\text { Flammable } \\
\text { gas }\end{array}$ & $\begin{array}{l}\text { Non- } \\
\text { flammable } \\
\text { gas }\end{array}$ \\
\hline GWP (Global Warming Potential) & 1610 & 1300 & 3 & 1030 \\
\hline ODP (Ozone Depletion Potential) & 0 & 0 & 0 & 0 \\
\hline
\end{tabular}




\section{EXPERIMENTAL APARATUS AND DATA REDUCTION}

\section{Experimental Setup}

The experimental setup consists of a refrigerant closed loop, shown in Fig. 1, and an auxiliary circuit, used to condensate and cool down the test fluid of the refrigerant loop. Both circuits are well detailed by do Nascimento et al. (2013) and Leão et al. (2014, 2015).

In the refrigerant circuit, the test fluid is driven by an oil-free gear micropump and the mass flow rate is measured by a Coriolis mass flow meter. Two needle valves were installed in the circuit main line, upstream the pre-heater and downstream of the test section, to minimize the propagation of instability effects from the test section to the remaining circuit and vice versa. A pre-heater consisting of a copper tube of a diameter of $12.7 \mathrm{~mm}$ wrapped with tapetype electrical resistances is installed upstream of the test section to heat up the test fluid to the desired inlet subcooling temperature.

The microchannels heat sink, schematically illustrated in Fig. 1, consists of a $28 \times 25 \times 4 \mathrm{~mm}^{3}$ copper block containing fifty parallel microchannels with width, depth, and total length of $123.3,494.2 \mu \mathrm{m}$ and $15 \mathrm{~mm}$, respectively. The distance between two

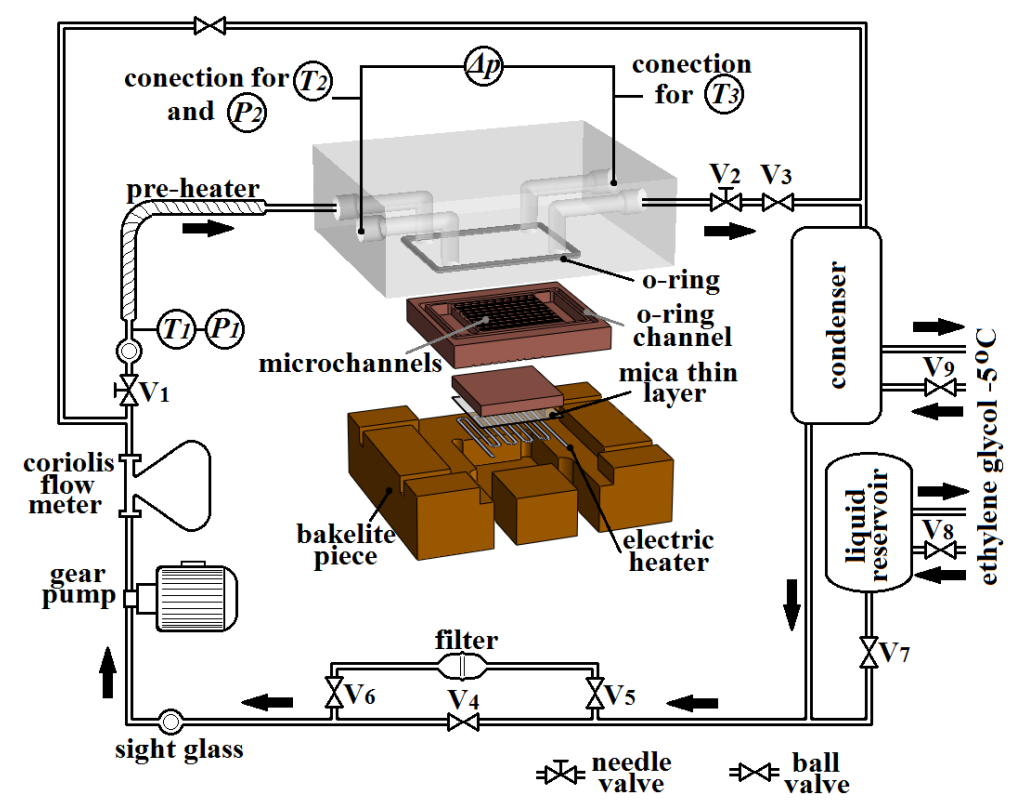

Figure 1. Schematics of the test section and the experimental setup (Leão et al., 2015).

consecutive microchannels is $176.9 \mu \mathrm{m}$. The surface roughness is $0.29 \mu \mathrm{m}$. The heat sink is covered with a transparent Pyrex cover plate of thickness of $15 \mathrm{~mm}$.

The test fluid is supplied to the inlet plenum and drained from the outlet plenum of the heat sink by channels with internal diameter of $3.5 \mathrm{~mm}$ machined through the Pyrex cover plate. A pair of channels positioned over the inlet and outlet plenums were fabricated in the Pyrex block. These channels were used to measure the absolute pressure at the test section inlet and the pressure drop along the test section. Thermocouples were positioned in these same channels to measure the bulk temperature at the inlet and outlet plenums.

On the backside of the heat sink, the wall temperature is measured through nine K-type thermocouples embedded within the heat sink wall and distributed according to a $3 \times 3$ matrix. A copper block was positioned between the electrical resistance and the heat sink to uniform the heat flux generated by the electrical resistance. The heating effect is obtained through a $0.5 \Omega$ electrical resistance composed by a continuous Kanthal wire bent as a serpentine.

The working fluid is condensate and subcooled in a plate-type heat exchanger by exchanging heat with the anti-freezing ethylene glycol aqueous solution from the auxiliary circuit. Downstream the plate-type heat exchanger, a pipeline connects the refrigerant tank and the refrigerant circuit. The refrigerant tank is used to control the saturation pressure at the refrigerant circuit. Downstream of the refrigerant tank and parallel to the main pipeline is an alternative pipeline, which has a filter drier used to remove possible particles dispersed in the refrigerant and installed between two ball valves.

The electrical signals of the measurements were acquired, processed and stored by a National Instruments SCXI-1000 chassis that communicates with the LabView software. The database analyzed in the present study comprises experimental results for mass velocities from 300 to $800 \mathrm{~kg} / \mathrm{m}^{2} \mathrm{~s}$, heat fluxes up to $320 \mathrm{~kW} / \mathrm{m}^{2}$ (based on the footprint area) and liquid subcooling at the test section inlet of 5 and $10^{\circ} \mathrm{C}$. Particularly in the present study, the results were obtained for the refrigerant R600a. The data for 
$\mathrm{R} 134 \mathrm{a}, \mathrm{R} 407 \mathrm{C}$ and R245fa were obtained in the same test facility and were previously published by do Nascimento et al. (2013) and Leão et al. (2014, 2015).

\section{Data Reduction}

The mass velocity, $\mathrm{G}$, is given as the ratio between the mass flow rate, $\overline{\mathrm{m}}$, measured by the Coriolis flow meter, and fifty times the cross sectional area of one single channel, so, assuming uniform mass flow distribution among the channels. Although neglected in the data reduction procedure, fluid maldistribution and flow instabilities causing reverse flow were observed during the experiments. However, measuring the flow rate and heat flux along each channel is not feasible. Moreover, the present paper concerns a comparative evaluation of the overall performance of the heat sink, what makes the present data regression procedure appropriate.

The amount of heat transferred to the fluid in the region of heat sink containing the microchannels, $\dot{\mathrm{Q}}_{\text {real }}$, is given by the electrical power supplied to the Kanthal resistance in the test section, $\dot{Q}_{\text {elet }}$, minus the heat losses to the environment, $\dot{\mathrm{Q}}_{\mathrm{env}}$, and the heat transferred to the fluid at the inlet and outlet plenums,

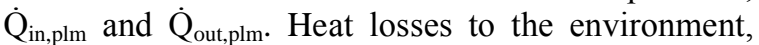
$\dot{Q}_{\text {env }}$, were evaluated from energy balances for singlephase flow tests. These energy balances are based on comparisons of the electrical power supplied to the heat sink and the product between the mass flow rate and the variation of enthalpy of the refrigerant between the inlet and outlet of the heat sink. This analysis reveals average heat losses to the environment ranging from 16 to $18 \%$ of the total electrical energy supplied to the heat sink. Adopting a parcel of heat losses equal to $17 \%$ of the imposed heating was found reasonable because comparisons of data for the heat transfer coefficient under singlephase flow conditions with well-established predictive methods from literature reveals deviations within the range of the uncertainties of their measurements. In fact, the maximum deviation between the experimental data and the heat transfer correlations of Stephan and Preußer (1979) and Li and $\mathrm{Wu}$ (2010) was less than $10 \%$. Therefore, even lower than the differences between the results predicted by these correlations.

The heat transferred to the fluid in the regions of the plena, $\dot{\mathrm{Q}}_{\text {in,plm }}$ and $\dot{\mathrm{Q}}_{\text {out,plm. }}$, was estimated based on the superficial area of the plena contacting the fluid, the local temperature of the refrigerant and the average temperature of the heat-sink, $\overline{\mathrm{T}}_{\text {wall }}$, evaluated based on the measurements of the thermocouples embedded within the heat sink wall. For this purpose, the heat transfer correlations of Stephan and Preußer (1979) and $\mathrm{Li}$ and $\mathrm{Wu}$ (2010) were used for singlephase and flow boiling conditions, respectively. In these analyses, it was assumed that heat is transferred only through the copper surface of the heat sink contacting the test fluid.

The effective heat flux, $\mathrm{q}^{\prime \prime}$ eff, was defined as the ratio between $\dot{\mathrm{Q}}_{\text {real }}$ and the heated area of the microchannels contacting the fluid given as the product of the heated perimeter, the channels length and the number of channels.

The average wall superheating of the heat sink, $\Delta \overline{\mathrm{T}}$, was calculated as the difference between the average temperature of the heat sink wall, $\overline{\mathrm{T}}_{\text {wall }}$, and the average temperature of the refrigerant along the microchannels length, $\overline{\mathrm{T}}_{\text {fluid. }}$. The average temperature of the test fluid along the microchannels was estimated considering a uniform heat flux along the channel surface and taking into account the lengths of the subcooled and saturated regions, assumed as single- and two-phase flow regions, respectively. The temperature at the end of the single-phase region, $\overline{\mathrm{T}}_{\text {end,1 } 1}$, and the single-phase pressure drop over this length were estimated based on the heat flux and the measured temperature and pressure at the inlet plenum of the heat sink by solving simultaneously an equation of state relating $\mathrm{p}_{\mathrm{sat}}$ and $\mathrm{T}_{\mathrm{sat}}$ plus energy balance and single-phase pressure drop equations. To estimate the temperature profile along the flow boiling region, the length of the microchannels corresponding to two-phase flow was discretized and for each element, the local pressure and vapor quality were determined based on energy balance over each discrete element and the corresponding pressure drop calculated according to the Homogenous model, with the two-phase dynamic viscosity given by the Maxwell Eucken 2 model (Awad and Muzychka, 2008; Levy, 1981). This procedure provided reasonable predictions of the pressure drop experimental data evaluated in the present study. The entrance and exit pressure drops due to the contraction and expansion at the inlet and outlet plena, the single-phase and acceleracional pressure drops were also considered. For experiments characterized by single-phase flow along all the channels length, the fluid temperature was given as the average temperature between measurements at the inlet and outlet plena.

Average heat transfer coefficients were estimated through the Newton's cooling law according to the following procedures: (i) effective heat transfer coefficient, $\overline{\mathrm{h}}_{\mathrm{eff}}$ corresponding to the overall heat transfer coefficient of the heat sink. These heat transfer coefficient data were considered to evaluate the overall heat transfer performance of the heat sink for the different fluids; (ii) two-phase heat transfer coefficient, $\overline{\mathrm{h}}_{\mathrm{TP}}$ considers only the region of the heat sink estimated as being under flow boiling conditions. The data for $\overline{\mathrm{h}}_{\mathrm{TP}}$ were considered for the comparisons with predictive methods from literature. The different definitions of heat transfer coefficients are given as follows:

$$
\overline{\mathrm{h}}_{\mathrm{eff}}=\frac{\mathrm{q}_{\mathrm{eff}}^{\prime \prime}}{\Delta \overline{\mathrm{T}}}
$$




$$
\overline{\mathrm{h}}_{\mathrm{TP}}=\frac{\mathrm{q}_{\mathrm{eff}}^{\prime \prime}}{\Delta \overline{\mathrm{T}}_{\mathrm{TP}}}
$$

where $\Delta \overline{\mathrm{T}}_{\mathrm{TP}}$ is the average wall superheating over the two-phase flow region of the heat sink, calculated as the difference between the average heat-sink wall temperature and the average temperature of the fluid over the two-phase flow region.

The average vapor quality over the heat sink, $\bar{x}$, was determined as the arithmetic average value of the thermodynamic vapor qualities at the inlet and outlet plena. The average vapor quality over the two-phase region, $\overline{\mathrm{x}}_{0}$, was defined as the arithmetic average value of the thermodynamic vapor qualities at the outlet plenum and at the onset of two-phase flow, corresponding to a thermodynamic vapor quality equal to zero.

Temperature measurements were calibrated and their uncertainties were evaluated according to the procedure proposed by Abernethy and Thompson (1973). For the remaining sensors and measuring devices, the uncertainties were assumed equal to the specifications provided by the manufacturers. Accounting for all instrument errors, uncertainties for the calculated parameter were estimated according the method of sequential perturbation of Moffat (1988) that considers that any measure $X_{i}$ presents a $\delta X_{i}$ uncertainty. The experimental uncertainties associated with the sensors and calculated parameters are presented in Tab. 2. Such estimations were performed using EES (Klein and Alvarado, 2002).

The experimental data presented in this paper were obtained by gradually increasing from a null value the heat flux until a maximum and then decreasing its value down to zero.

The experimental apparatus and the data regression procedures were validated by comparing single-phase flow data against predictions from wellestablished correlations from literature for pressure drop and heat transfer coefficient. The data considered in the validation process were obtained for R245fa as presented by Leão et al. (2015). The method of Shah and London (1978) for rectangular channel and laminar flow captured reasonably well the experimental trends for the frictional pressure drop, and the method of Stephan and Preußer (1979) for laminar flow, uniform heat flux, simultaneous developing flow region and circular ducts also captured reasonably well the trends of the experimental results for heat transfer coefficient.

For those interested on a detailed description of the data regression procedure, the previous paper by Leão et al. (2015) is recommended as reference.

Table 2. Uncertainties of measured and calculated parameters.

\begin{tabular}{lc}
\hline \multicolumn{1}{c}{ Parameters } & Uncertainty \\
\hline $\mathrm{H}[\mu \mathrm{m}]$ & 22.9 \\
$\mathrm{~W}[\mu \mathrm{m}]$ & 15.4
\end{tabular}

\begin{tabular}{lc}
$\mathrm{L}[\mu \mathrm{m}]$ & 5 \\
$\mathrm{G}\left[\mathrm{kg} / \mathrm{m}^{2} \mathrm{~s}\right]$ & 132 \\
$\mathrm{~T}\left[{ }^{\circ} \mathrm{C}\right]$ & 0.15 \\
$\overline{\mathrm{T}}_{\text {wall }}\left[{ }^{\circ} \mathrm{C}\right]$ & 0.4 \\
$\overline{\mathrm{T}}_{\text {fluid }}\left[{ }^{\circ} \mathrm{C}\right]$ & 0.2 \\
$\Delta \overline{\mathrm{T}}\left[{ }^{\circ} \mathrm{C}\right]$ & 0.45 \\
$\Delta \mathrm{T}_{\text {sub }}\left[{ }^{\circ} \mathrm{C}\right]$ & 0.3 \\
$\mathrm{p}[\mathrm{kPa}]$ & 2 \\
$\Delta \mathrm{p}[\mathrm{kPa}]$ & 0.2 \\
$\mathrm{q}=\left[\mathrm{kW} / \mathrm{m}^{2}\right]$ & 0.8 \\
$\overline{\mathrm{h}}\left[\mathrm{kW} /\left(\mathrm{m}^{2} .{ }^{\circ} \mathrm{C}\right)\right]$ & 1.3 \\
\hline
\end{tabular}

\section{ANALYSIS OF THE EXPERIMENTAL} RESULTS

\section{Heat Transfer Coefficient Results}

Figure 2 displays a comparison of boiling curves for refrigerants R134a, R407C, R245fa and R600a for mass velocity of $328 \mathrm{~kg} /\left(\mathrm{m}^{2} . \mathrm{s}\right)$ and degree of subcooling at the inlet plenum of $5{ }^{\circ} \mathrm{C}$. According to this figure, initially the heat flux increases almost linearly with increasing wall superheating. Then, the curves display discontinuities that result from a transition from a condition of only single-phase flow along all the channels to a condition with the presence of nucleate boiling. This phenomenon, named in literature as the onset of nucleate boiling (ONB), is related to the fact that an excess of superheating is necessary to trigger the boiling process. For results obtained by decreasing gradually the heat flux, as shown in Fig. 2, the nucleation sites are already active and, therefore, an excess of superheating is not necessary. This behavior implies that the boiling curves for increasing and decreasing heat flux do not follow the same path.

During the experimental campaign, care was exercised in order to identity the onset of nucleate boiling (ONB) corresponding to the superheating excess necessary to trigger the boiling process. So, before running the experiments and obtaining the data corresponding each boiling curve, the refrigerant inside the test section was maintained for 72 hours as quiescent liquid without heating. Such a procedure was adopted to deactivate the cavities and eliminate vapor nucleus on the heat sink surface that would favor an earlier ONB.

According to Fig. 2, the fluid R407C presents the lowest excess of superheating, followed by the refrigerants R134a, R600a and R245fa. Values higher than $12^{\circ} \mathrm{C}$ can be noted in Fig. 2 for the refrigerant R245fa. As shown in Tab. 1, the refrigerants R245fa and R600a present lower vapor density and higher surface tension than the refrigerants R407C and R134a. Therefore, the refrigerants R245fa and R600a require higher wall superheating to activate the cavities. High wall superheating to achieve the ONB is not desirable because this can lead either to a premature surface dryout or to a wall temperature higher than the safe value for the electronic device. 
This scenario becomes critical during startups of electronic devices, characterized by the absence of active nucleate boiling sites along the wet surface of the heat sink.

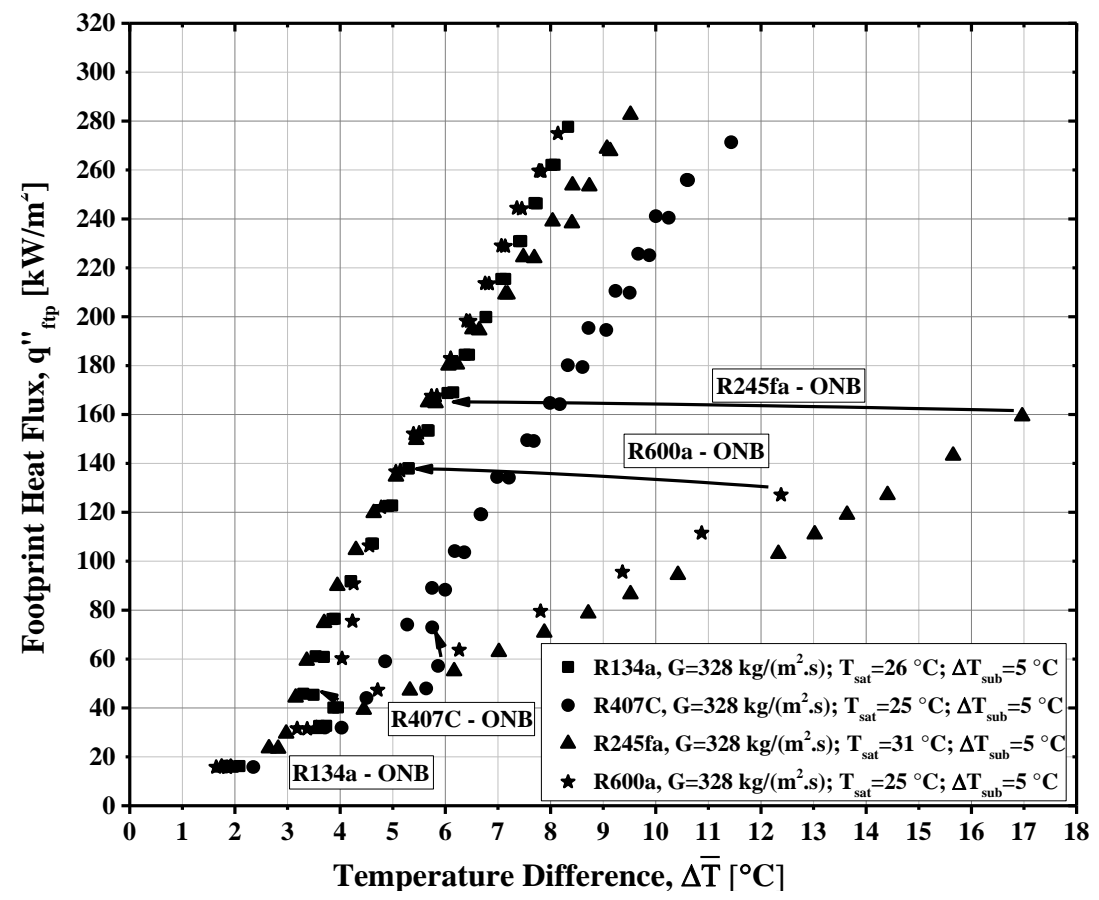

Figure 2. Boiling curves of refrigerants R134a, R407C, R245fa R600a for liquid subcooling at the inlet plenum of $5^{\circ} \mathrm{C}$ and mass velocity of $328 \mathrm{~kg} /\left(\mathrm{m}^{2} . \mathrm{s}\right)$.

Bergles and Rohsenow (1964), Davis and Anderson (1966) and Kandlikar et al. (2006), just to mention a few authors, proposed criteria for determining the minimum wall superheating necessary to the onset of nucleate boiling. Kandlikar et al. (2006) proposed a criterion to predict the ONB giving by the following equation:

$$
\Delta \mathrm{T}_{\text {sub, ONB }}=\frac{\mathrm{q}^{\prime \prime}}{\overline{\mathrm{h}}}-\Delta \mathrm{T}_{\text {sat }, \text { ONB }}=\frac{\mathrm{q}^{\prime \prime}}{\overline{\mathrm{h}}}-\sqrt{\frac{8 \cdot 8 \cdot \sigma \cdot \mathrm{T}_{\mathrm{sat}} \cdot \mathrm{q}^{\prime \prime}}{\rho_{\mathrm{v}} \cdot \mathrm{i}_{\mathrm{lv}} \cdot \mathrm{k}_{\mathrm{l}}}}
$$

Table 3 illustrates a comparison between experimental data for the ONB obtained in the present study and the corresponding predictions given by the method of Kandlikar et al. (2006). According to this table, the method of Kandlikar et al. (2006) provides reasonable predictions of the experimental data. In general, the method under predicted the data with an error lower than $20 \%$, independently of the fluid.

Table 3. Comparison between experimental results and predictive methods for Onset of Nucleated Boiling under subcooled flow boiling conditions.

\begin{tabular}{cccccc}
\hline Fluid & $\mathbf{h}\left[\mathbf{k W} /\left(\mathbf{m}^{\mathbf{2}}{ }^{\mathbf{o}} \mathbf{C}\right)\right]$ & Heat flux $\left[\mathbf{k W} / \mathbf{m}^{2}\right]$ & $\mathbf{T}_{\text {sat }}[\mathbf{K}]$ & $\begin{array}{c}\Delta \mathbf{T}_{\text {sub,ONB }} \\
\text { calculated [K] }\end{array}$ & $\begin{array}{c}\Delta \mathbf{T}_{\text {sub,ONB }} \\
\text { experimental }[\mathbf{K}]\end{array}$ \\
\hline R134a & 2.36 & 8.82 & 298.6 & 3.09 & 3.73 \\
R407C & 2.30 & 12.93 & 298.3 & 5.04 & 5.64 \\
R245fa & 2.53 & 43.00 & 303.3 & 13.68 & 16.97 \\
R600a & 2.77 & 34.30 & 298.2 & 10.59 & 12.38 \\
\hline
\end{tabular}

Figure 3 displays the effect of the mass velocity and the degree of liquid subcooling at the microchannels inlet on the variation of the average effective heat transfer coefficient with increasing the average thermodynamic vapor quality for the refrigerant R600a. Experimental data corresponding single-phase flow conditions along the heat spreader are highlighted by circles containing the symbols corresponding to the data points. Under conditions of single-phase flow, Fig. 3a shows that, the effect of the variation of liquid subcooling on $\overline{\mathrm{h}}_{\mathrm{eff}}$ is almost negligible due to marginal changes of the transport properties with increasing fluid temperature at the inlet plenum. According to Fig. 3a, for a fixed value of $\bar{x}$ and under conditions of nucleate boiling and low average vapor qualities, the average effective heat transfer coefficient increases with increasing the liquid subcooling. However, the effect of liquid subcooling on $\overline{\mathrm{h}}_{\text {eff }}$ decreases with increasing the average vapor quality until a certain value of $\bar{x}$ from 
which its effect on $\bar{h}_{\text {eff }}$ becomes negligible. Collier and Thome (1994) pointed out that the condition characterized by the ratio of heat flux and surface temperature independent of the liquid subcooling corresponds to fully developed subcooled boiling. Under this condition, the increment of heat flux is followed by the increase of surface temperature and the contribution of single-phase forced convection to the heat transfer rate becomes relatively negligible. In fully developed subcooled boiling, the whole surface is covered with nucleation sites and the vapor is generated in the form of isolated bubbles at preferred nucleation points. Such behaviors were already pointed out in the previous studies for refrigerants R134a, R407C and R245fa (do Nascimento et al., 2013; Leão et al., 2015, 2014).

Figure $3 \mathrm{~b}$ illustrates the effect of the mass velocity on the average effective heat transfer coefficient. According to this Figure, $\overline{\mathrm{h}}_{\mathrm{eff}}$ increases with increasing mass velocity. For only single-phase flow along the channels, this behavior was already expected and agrees with the predictions given by the method of Stephan and Preußer (1979) for laminar flow, uniform heat flux and simultaneous developing flow region. Under the presence of flow boiling along the channels, the fact that the average effective heat transfer coefficient increases with increasing mass velocity seems related to the augmentation of heat flux to maintain $\bar{x}$ with increasing mass velocity. This hypothesis is presented based on the work of Kanizawa et al. (2016) according to which nucleate boiling effects are dominant under conditions of low vapor quality, implying that the heat transfer coefficient increases with increasing heat flux as given by the predictive method of Cooper (1984) for pool boiling. In fact, Tibiriçá and Ribaski (2014) based on high-speed images of flow boiling for a quartz $400 \mu \mathrm{m}$ I.D. tube observed active nucleation sites and bubbles departure under conditions of annular and elongated flow patterns. The behaviors

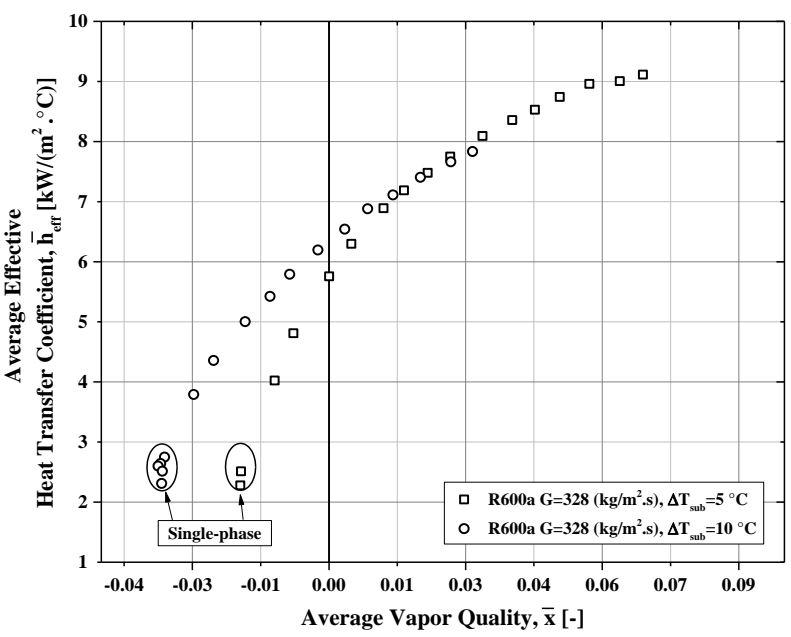

A displayed in Fig. 4 corroborate the predominance of nucleate boiling effects. According to this figure, the heat transfer coefficient to both mechanisms increases with increasing heat flux. However, the increment of the heat transfer coefficient for pool boiling is steeper than for flow boiling. This behavior is explained by the fact that for flow boiling, the average vapor quality and, consequently, nucleate boiling suppression effects, increases with increasing heat flux, causing a lower increment of $\bar{h}_{\mathrm{TP}}$ with increasing heat flux for flow boiling than for pool boiling. Similar behaviors concerning the effect of the mass velocity on $\bar{h}_{\text {eff }}$ observed for R600a in the present study were pointed out for R134a, R407C and R245fa in the previous studies (do Nascimento et al., 2013; Leão et al., 2014, 2015).

Figures 5 and 6 present comparisons of the average effective heat transfer coefficient of the refrigerants R600a, R134a, R407C and R245fa. According to this figures, the refrigerant R600a provides the highest average effective heat transfer coefficient. By comparing Figs. 5 and 6, it can be noted that, under conditions of two-phase flows along the channels and a fixed average vapor quality, the difference on the average effective heat transfer coefficient among the four fluids decreases with increasing mass velocity and liquid subcooling.

\section{Comparision of Experimental Results and Prediction Methods}

This item compares experimental results for the two-phase heat transfer coefficient $\overline{\mathrm{h}}_{\mathrm{TP}}$ against corresponding predictions based on six flow boiling heat transfer predictive methods available in the literature. Initially, the methods considered in the present comparison are briefly described. Then, the statistical parameters extracted from the comparisons are presented and discussed. Finally, the heat transfer behaviors according to the experimental results and

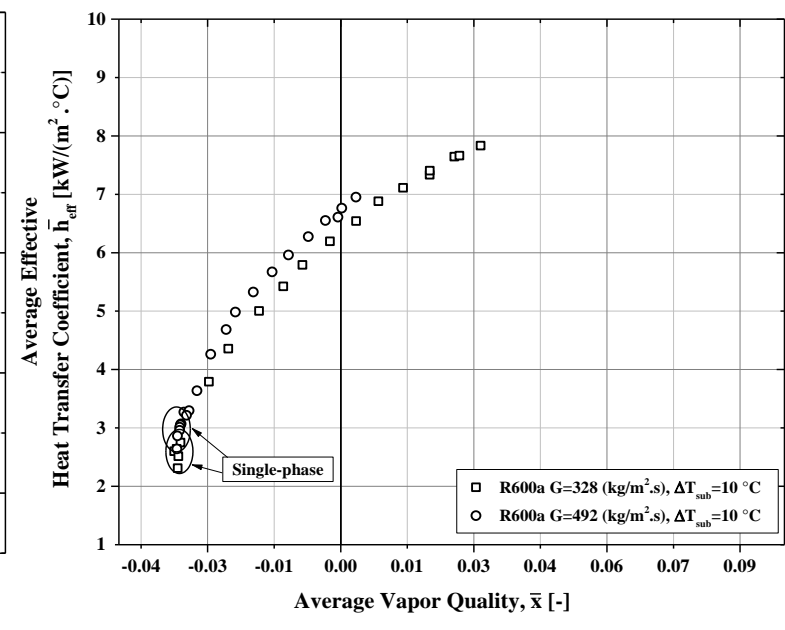

B

Figure 3. Illustration of (A) the effect of liquid subcooling degree and (B) mass velocity on the variation of the average effective heat transfer coefficient with average vapor quality for R600a and saturation temperature of $25 \mathrm{C}$. 


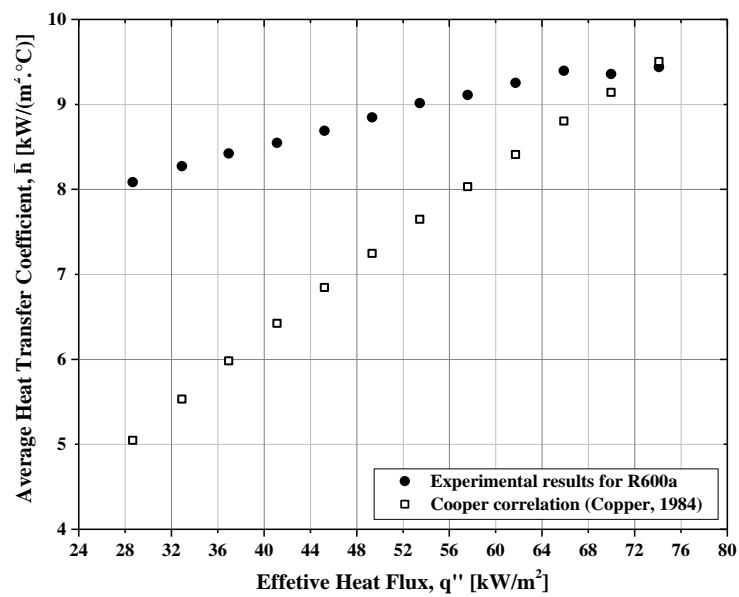

Figure 4. Illustration of the comparison between the average effective heat transfer coefficient and the heat transfer coefficient according to the pool boiling correlation of Cooper (1984) for R600a with saturation temperature of $25^{\circ} \mathrm{C}$, liquid subcooling at the inlet plenum of $5^{\circ} \mathrm{C}$ and mass velocity of $328 \mathrm{~kg} /\left(\mathrm{m}^{2} . \mathrm{s}\right)$.

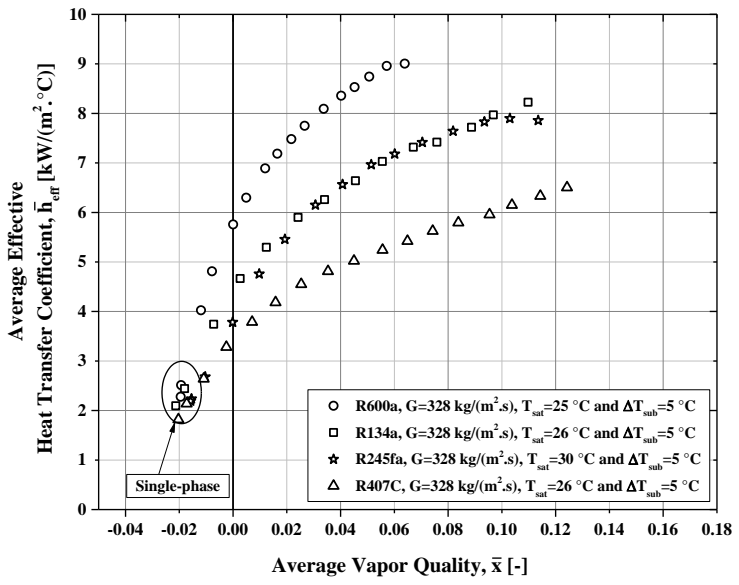

A

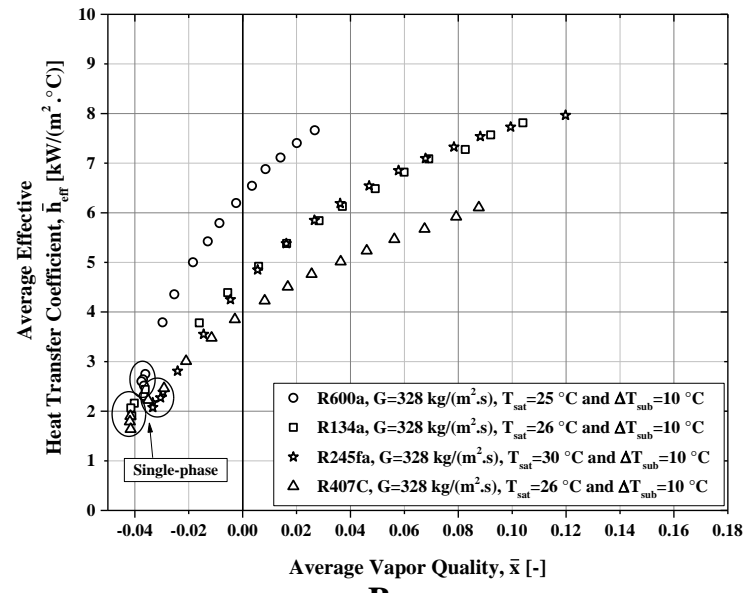

B

Figure 5. Illustration of the effect of fluid refrigerant on the variation of the average effective heat transfer coefficient with average vapor quality for liquid subcooling degree at the inlet plenum of (A) $5^{\circ} \mathrm{C}$ and (B) $10^{\circ} \mathrm{C}$ and mass velocity of $328 \mathrm{~kg} /\left(\mathrm{m}^{2} . \mathrm{s}\right)$.

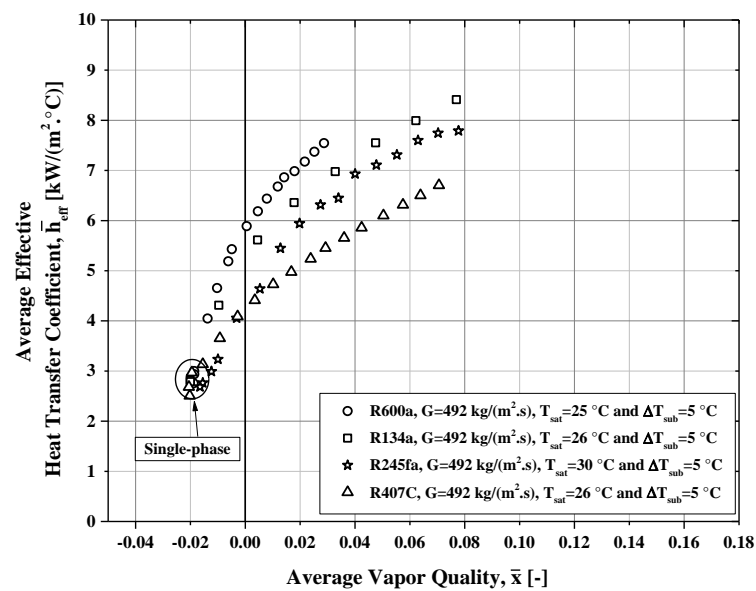

A



B

Figure 6. Illustration of the effect of fluid refrigerant on the variation of the average effective heat transfer coefficient with average vapor quality for liquid subcooling degree at the inlet plenum of (A) $5{ }^{\circ} \mathrm{C}$ and (B) $10^{\circ} \mathrm{C}$ and mass velocity of $492 \mathrm{~kg} /\left(\mathrm{m}^{2} . \mathrm{s}\right)$. 
the predictive methods are compared and analyzed. For comparison purposes and based on the experimental conditions, the methods were implemented along the two-phase length over discrete elements considering local vapor quality and fluid properties. Then, the average heat transfer coefficient over the two-phase length was calculated. The comparisons were performed for refrigerants R134a, R407C, R245fa and R600a and includes the methods of Liu and Winterton (1991), Thome et al. (2004), Saitoh et al. (2007), Bertsch et al. (2009), Li and Wu (2010), Kim and Mudawar (2013) and Kanizawa et al. (2016).

Liu and Winterton (1991) based on Chen's work (Chen, 1966), wherein the flow boiling heat transfer coefficient is given as the superposition of forced convection and nucleated boiling effects, developed a method to predict the heat transfer coefficient for subcooled and saturated convective boiling. To capture the amplification of the effects of nucleate boiling, for low vapor qualities, and of forced convection, for high vapor qualities, these authors adopted suggestion posted by Kutateladze (1961) by employing an asymptotic constant of 2 in a power-law model. The heat transfer predictive method proposed by Liu and Winterton (1991) for single conventional channels is commonly found in the literature being compared against macro- and micro-scale experimental results.

Thome et al. (2004) proposed the 3-zones model to describe the evaporation process in microchannels during the passage of an elongated bubble. The heat transfer model consists of quantifying the variation of the local heat transfer coefficient during the cyclic passage of a liquid slug, an elongated bubble and, if the case, a vapor slug in the absence of a liquid film on the tube wall at the bubble tail. According to Dupont et al. (2004) and Ribatski (2013), based on analyses of broad databases from literature, the 3zones model is qualitatively able to capture the effects of heat flux, mass velocity, vapor quality and bubble confinement on the tendencies of the heat transfer coefficient. Except for the minimum film thickness assumed as the surface roughness as suggested by Costa-Patry et al. (2011), the empirical constants presented by Dupont et al. (2004) were considered for the implementation of the three-zone model in the present study. The combination of Cioncolini and Thome (2011) method, for annular flow, and Thome et al. (2004) method, for elongated bubble flow, with the transition between these flow patterns given according to Ong and Thome (2011), as proposed by Costa-Patry et al. (2012), was also evaluated in the present study. Nonetheless, worst predictions of the experimental data than those by Thome et al. (2004) were obtained.

The method of Saitoh et al. (2007) is also a Chen's approach (Chen, 1966) for the pre-dryout region and adopts a proration according to the local vapor quality between the heat transfer coefficient for $\mathrm{x}=\mathrm{x}_{\text {dryout }}$ and $\mathrm{x}=1$. Saitoh et al. (2007) adjusted the empirical constants of their method based on experimental results only for $\mathrm{R} 134 \mathrm{a}$, for single channels and tube diameter ranging from 0.51 to $10.92 \mathrm{~mm}$.

Bertsch et al. (2009) proposed a flow boiling heat transfer predictive method also based on Chen's approach (Chen, 1966) and considering an extensive database (3899 data points from 14 studies in the literature for single and parallel multi-microchannels configurations). The method of Bertsch et al. (2009) takes into account the effects of heat flux, mass velocity, vapor quality and bubble confinement.

$\mathrm{Li}$ and $\mathrm{Wu}$ (2010) have compared seven methods for prediction of the heat transfer coefficient with 3744 experimental data points gathered from graphs and tables available in the literature. The database obtained by them is restricted to saturated flow boiling and covers a broad number of fluids (including hydrocarbons) and channels hydraulic diameters varying from 0.16 to $3.1 \mathrm{~mm}$ for multi and single-channel configurations. Based on the results from their comparison, the authors pointed out unsatisfactory predictions by the methods from literature. However, they highlighted that the deviations of the predictive methods from the experimental trends are not necessarily related to the weaknesses of the methods, but to the unique and complex nature of flow boiling in microchannels. $\mathrm{Li}$ and $\mathrm{Wu}$ (2010) also proposed a simple correlation to predict the heat transfer coefficient during flow boiling in small diameter channels. In their correlation, the Nusselt number is given as function of the Boiling, Reynolds and Bond numbers.

Kim and Mudawar (2013), based on more than ten thousand data points gathered in the literature, proposed a new method for prediction of the flow boiling heat transfer coefficient in small diameter tubes for pre-dryout conditions. As Liu and Winterton (1991), their method is based on the superposition of nucleate boiling and convective effect and assumes an asymptotic exponent of 2 .

Most recently, Kanizawa et al. (2016) developed a method for prediction of the heat transfer coefficient in small diameter channels that considers pre-dryout and post-dryout regions as initially proposed by Saitoh et al. (2007). The empirical constants of their method were adjusted based on a broad database comprising more than 2000 data points for refrigerants R134a, R245fa and R600a and tube internal diameter from 0.38 to $2.6 \mathrm{~mm}$. In the method of Kanizawa et al. (2016), nucleate boiling effects are taken into account through the correlations of Stephan and Abdelsalam (1980) for pool boiling of halocarbon and hydrocarbon refrigerants. Convective effects are estimated according to the correlation of Dittus and Boelter (1985), assuming only the liquid phase flowing in the channel. In their method, the enhancement factor of convective effects and the suppression nucleation factor are based on the in situ 
gas velocity estimated according to the void fraction prediction method proposed recently by Kanizawa and Ribatski (2016).

Figure 7 shows the comparison of the experimental results for the average heat transfer coefficient over the two-phase length and the corresponding predictions provided by the methods from literature. In general, the experimental data for R407C are overestimated by the methods. Except by Liu and Winterton (1991) that underestimate the data for R134a, Kanizawa et al. (2016), Kim and Mudawar (2013), Li and Wu (2010), Bertsch et al. (2009), Saitoh et al. (2007) and Thome et al. (2004) overestimate most of results for this refrigerant. $\mathrm{Li}$ and $\mathrm{Wu}$ (2010) (see Fig. 7c) overestimate the data of R245fa with a deviation lower than $30 \%$ while the other methods underestimate the same data. The methods of $\mathrm{Li}$ and $\mathrm{Wu}$ (2010), Saitoh et al. (2007) predicts most of results for R600a within an error band of 0 to $30 \%$.

Table 5 depicts the results of the comparisons of experimental and predicted data according to the following criteria: the fraction of data predicted

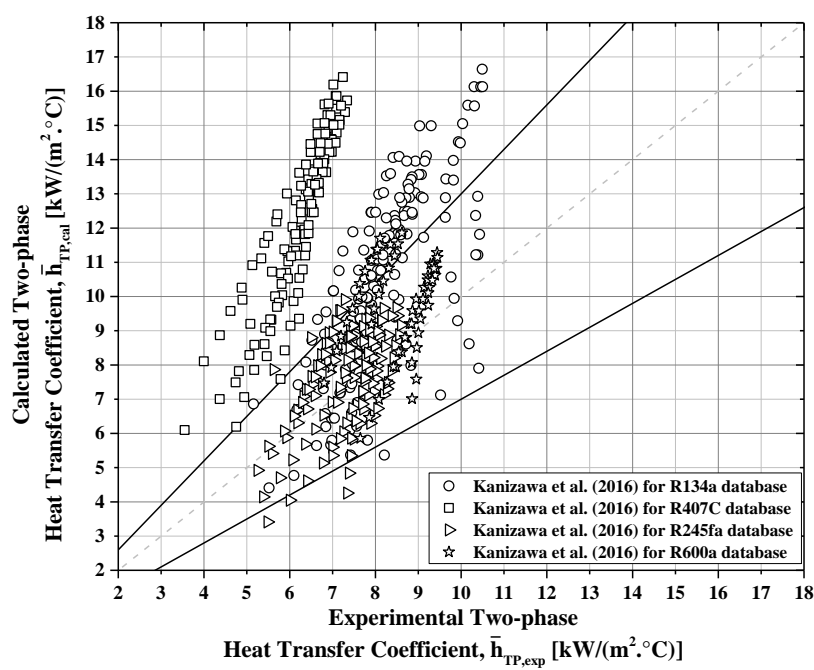

A

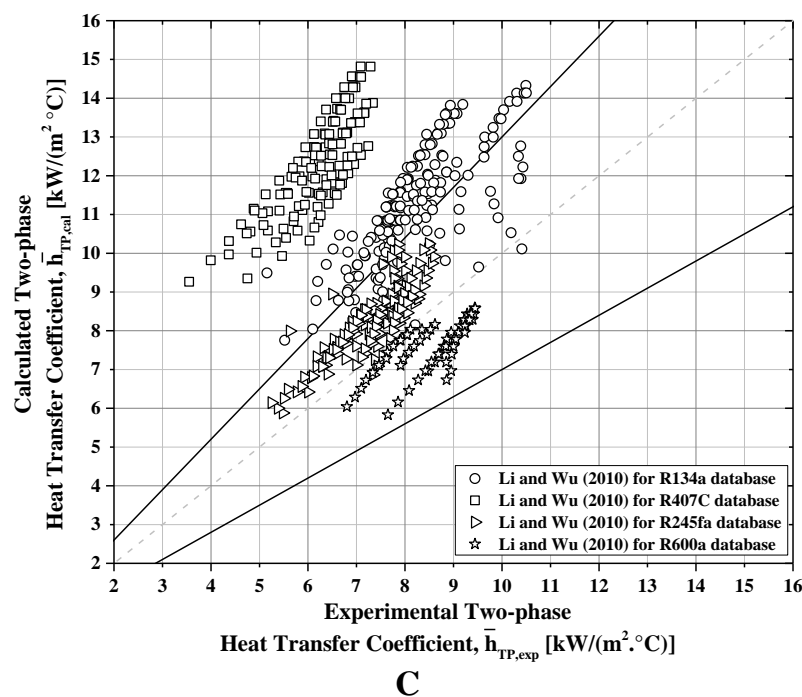

within an error band of $\pm 30 \%$, $\xi$, and the mean absolute error, $\eta$. According to this table, the methods of Bertsch et al. (2009), Saitoh et al. (2007), Thome et al. (2004) and Liu and Winterton (1991) provided reasonable predictions of the experimental results for the refrigerant R134a. The methods of Kanizawa et al. (2016), Kim and Mudawar (2013), Li and Wu (2010), Bertsch et al. (2009), Saitoh et al. (2007) and Liu and Winterton (1991) predicted more than $80 \%$ of experimental results for R245fa within an error band of $\pm 30 \%$ and provided a mean absolute error lower than $20 \%$. The methods of Kanizawa et al. (2016), Li and Wu (2010), Saitoh et al. (2007) and Liu and Winterton (1991) provided reasonable predictions of the R600a data, predicting more than $80 \%$ of the data within an error band of $\pm 30 \%$. No one of the methods evaluated in the present study provided accurate predictions of the heat transfer coefficient for R407C. It can be speculated that this result is due to the fact that this refrigerant is a zeotropic mixture, and none of the evaluated method includes refrigerant mixtures in the databases used in their development.

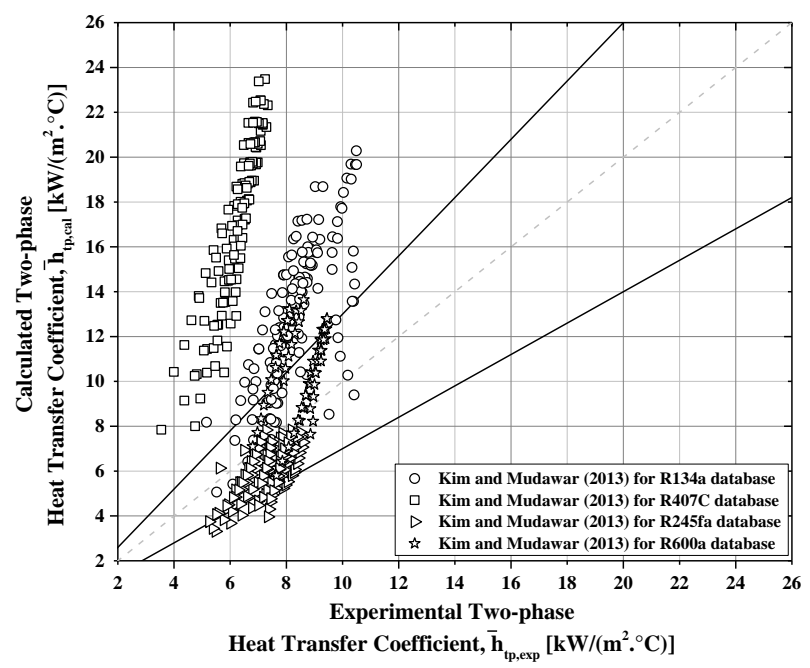

B

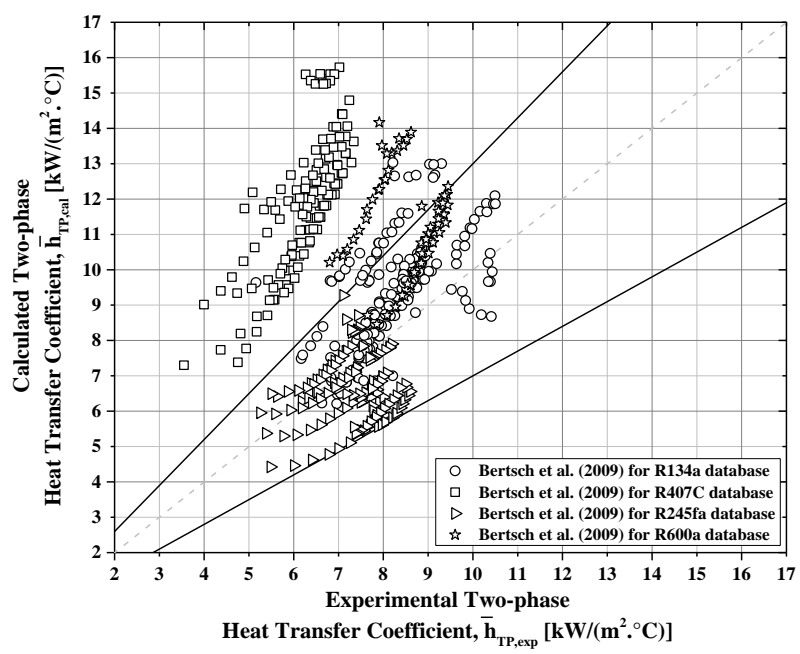

D 


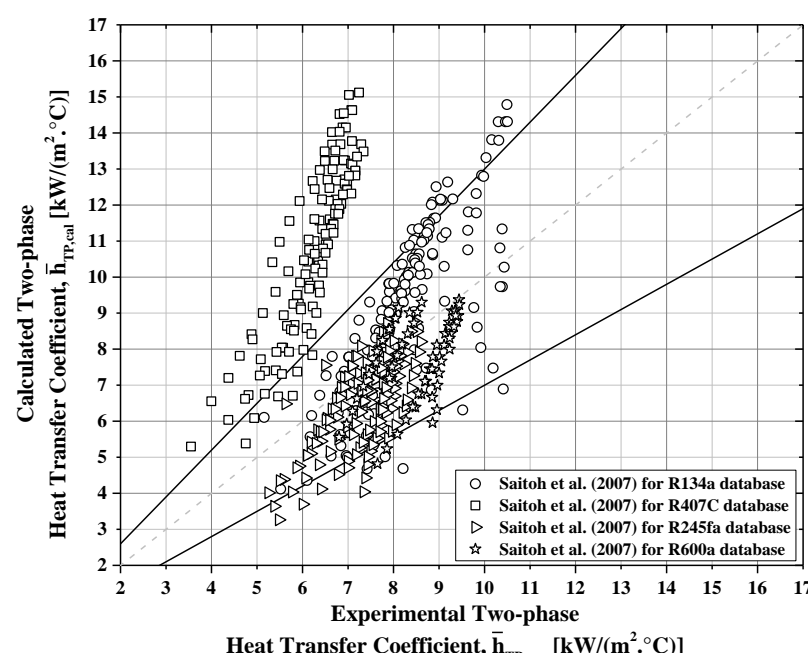

E

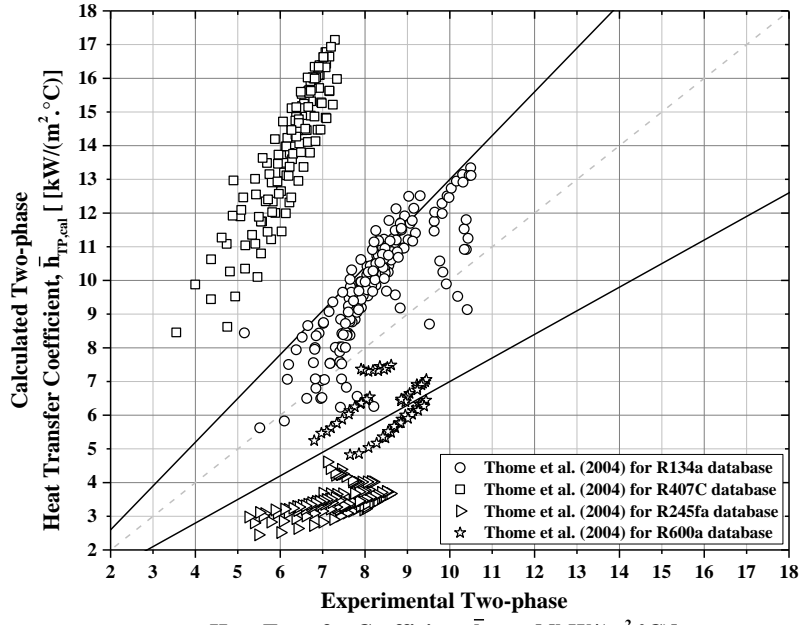

Heat Transfer Coefficient, $\overline{\mathbf{h}}_{\mathrm{TP}, \exp }\left[\left[\mathrm{kW} /\left(\mathrm{m}^{2} \cdot{ }^{\circ} \mathrm{C}\right)\right]\right.$

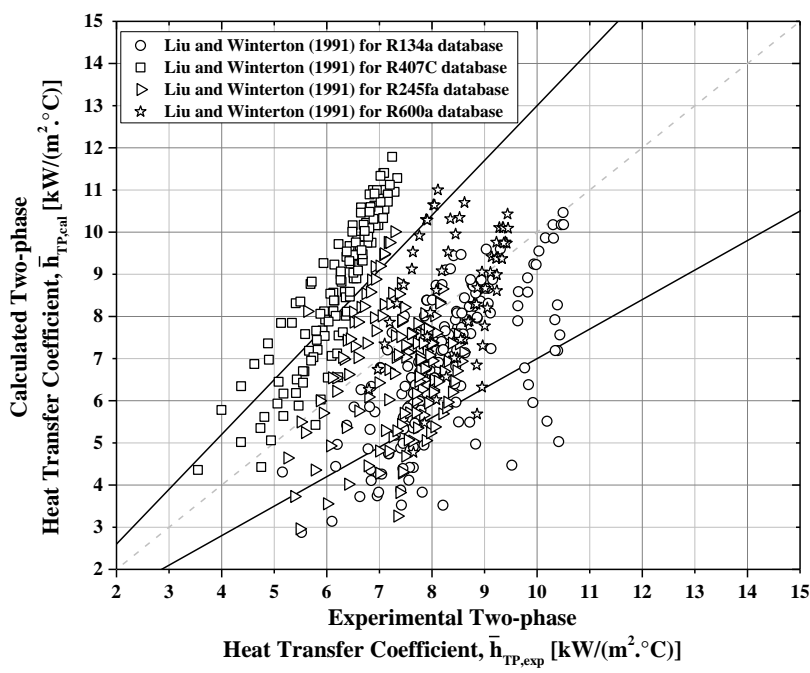

G

Figure 7. Comparison of the experimental results for $\overline{\mathrm{h}}_{\mathrm{TP}}$ of the refrigerants R134a, R407C, R245fa and and the respective predictions through the methods of (A) Liu and Winterton (1991), (B) Bertsch et al. (2009), (C) Saitoh et al. (2007) (D) Kanizawa et al. (2016), (E) Thome et al. (2004), (F) Li and Wu (2010) and (G) Kim and Mudawar (2013).

Table 5. Statistical parameter of the comparison between experimental results and predictive methods for heat transfer coefficient.

\begin{tabular}{|c|c|c|c|c|c|c|c|c|}
\hline & & 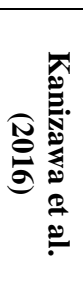 & 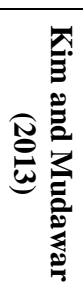 & 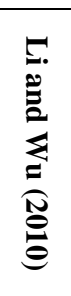 & 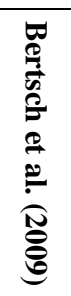 & 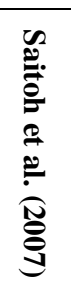 & 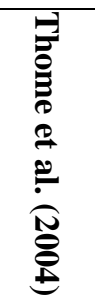 & 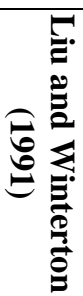 \\
\hline \multirow{2}{*}{$\begin{array}{c}\text { R134a (do } \\
\text { Nascimento } \\
\text { et al., 2013) }\end{array}$} & Mean absolute Error, $\boldsymbol{\eta}[\%]$ & 31.6 & 52.1 & 37.3 & 16.3 & 18.2 & 20.7 & 18.3 \\
\hline & $\begin{array}{c}\text { Data predicted to within } \pm 30 \%, \xi \\
{[\%]}\end{array}$ & 46.3 & 23.4 & 22.3 & 82.3 & 82.9 & 86.9 & 78.9 \\
\hline \multirow{2}{*}{$\begin{array}{l}\text { R407C (Leão } \\
\text { et al., 2014) }\end{array}$} & Mean absolute Error, $\eta[\%]$ & 95.4 & 169.8 & 98.6 & 90.4 & 71.2 & 123.5 & 39.5 \\
\hline & $\begin{array}{c}\text { Data predicted to within } \pm 30 \%, \xi \\
{[\%]}\end{array}$ & 0.0 & 0.0 & 0.00 & 0.0 & 4.6 & 0.0 & 26.2 \\
\hline \multirow{2}{*}{$\begin{array}{c}\text { R245fa } \\
\text { (Leão et al., } \\
\text { 2015) }\end{array}$} & Mean absolute Error, $\eta[\%]$ & 13.7 & 17.8 & 13.4 & 14.4 & 13.9 & 52.5 & 18.1 \\
\hline & $\begin{array}{c}\text { Data predicted to within } \pm 30 \%, \xi \\
{[\%]}\end{array}$ & 92.1 & 85.0 & 97.9 & 99.3 & 90.7 & 0.0 & 80.0 \\
\hline
\end{tabular}




\begin{tabular}{|c|c|c|c|c|c|c|c|c|}
\hline \multirow[b]{2}{*}{ R600a } & Mean absolute Error, $\eta[\%]$ & 18.1 & 27.0 & 10.9 & 34.0 & 12.1 & 26.0 & 13.8 \\
\hline & $\begin{array}{c}\text { Data predicted to within } \pm 30 \%, \xi \\
{[\%]}\end{array}$ & 79.4 & 65.1 & 100.0 & 63.5 & 93.7 & 52.4 & 88.9 \\
\hline \multirow{2}{*}{$\begin{array}{c}\text { All the } \\
\text { database }\end{array}$} & Mean absolute Error data, $\eta[\%]$ & 41.4 & 69.9 & 43.3 & 36.9 & 29.9 & 56.6 & 23.2 \\
\hline & $\begin{array}{l}\text { Data predicted within an error band } \\
\text { of } \pm 30 \%, \xi[\%]\end{array}$ & 50.9 & 38.8 & 46.7 & 63.0 & 66.1 & 37.2 & 66.7 \\
\hline
\end{tabular}

Figures 8 to 11 illustrates the variation of $\overline{\mathrm{h}}_{\mathrm{TP}}$ with $\overline{\mathrm{x}}_{0}$ according to the experimental data and the predictive methods evaluated in the present study. According to Figs. 7 to 10, the method of $\mathrm{Li}$ and $\mathrm{Wu}$ (2010) and Thome et al. (2004) were the best in order to capture the trend of gradual increase of $\overline{\mathrm{h}}_{\mathrm{TP}}$ with $\overline{\mathrm{x}}_{0}$. The methods of Kanizawa et al. (2016), Bertsch et al. (2009), Saitoh et al. (2007) and Liu and Winterton (1991) capture also the trend of $\overline{\mathrm{h}}_{\mathrm{TP}}$ with $\overline{\mathrm{x}}_{0}$, however, these methods predicts a much higher gradient for the heat transfer coefficient. The method of Kim and Mudawar (2013) was the worst to predict the heat transfer coefficient trends providing the highest gradient for the $\overline{\mathrm{h}}_{\mathrm{TP}}$ with increasing $\overline{\mathrm{x}}_{0}$. Based on the analysis presented in this item and the results given in

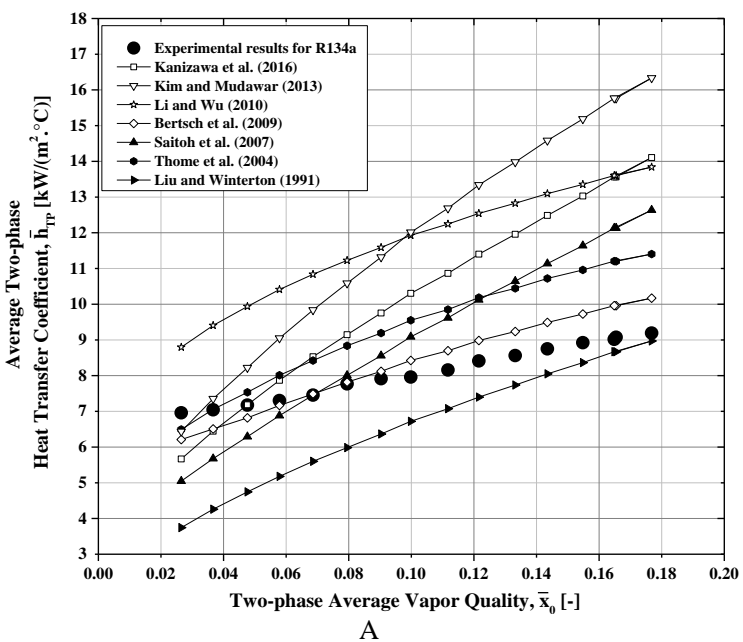

Tab. 5, it can be concluded that none of the methods provides satisfactory predictions of the heat transfer coefficient under flow boiling conditions for all refrigerants. Considering only pure fluid (R134a, R245fa and R600a data), Liu and Winterton (1991), Saitoh et al. (2007) and Bertsch et al. (2009) provided reasonable results, predicting more than $80 \%$ of the data within an error band of $\pm 30 \%$ and providing mean absolute errors lower than 20\%. Curiously, despite of being remarkably simple, the method proposed by $\mathrm{Li}$ and $\mathrm{Wu}(2010)$ captures the trend of $\overline{\mathrm{h}}_{\mathrm{TP}}$ with $\overline{\mathrm{x}}_{0}$ and provided the highest $\xi$ and the lowest $\eta$ for the refrigerants R245fa and R600a.

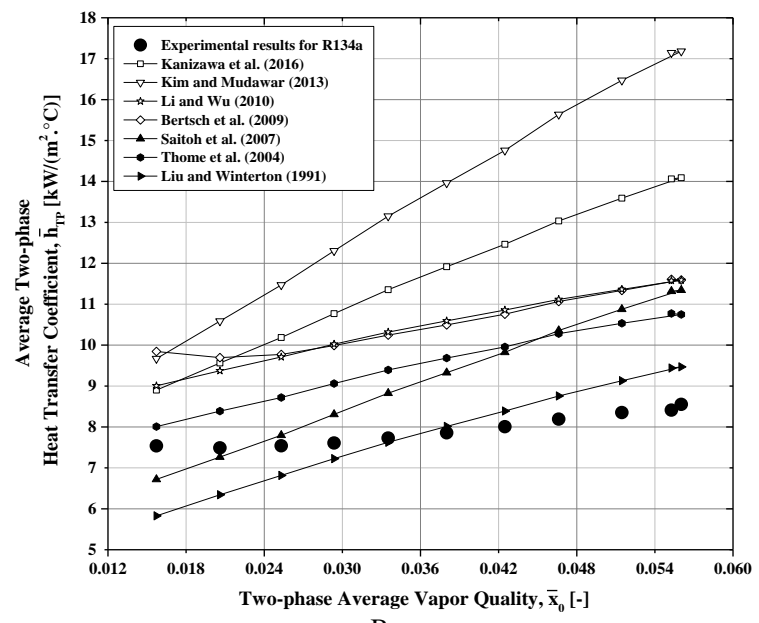

B

Figure 8. Comparison of the trends of $\overline{\mathrm{h}}_{\mathrm{TP}}$ with varying $\overline{\mathrm{x}}_{0}$ according to the experimental results and the predictive methods from literature for R134a, liquid subcooling of $5^{\circ} \mathrm{C}$ and mass velocities of (A) $328 \mathrm{~kg} /\left(\mathrm{m}^{2} . \mathrm{s}\right)$ and (b) $820 \mathrm{~kg} /\left(\mathrm{m}^{2} . \mathrm{s}\right)$.

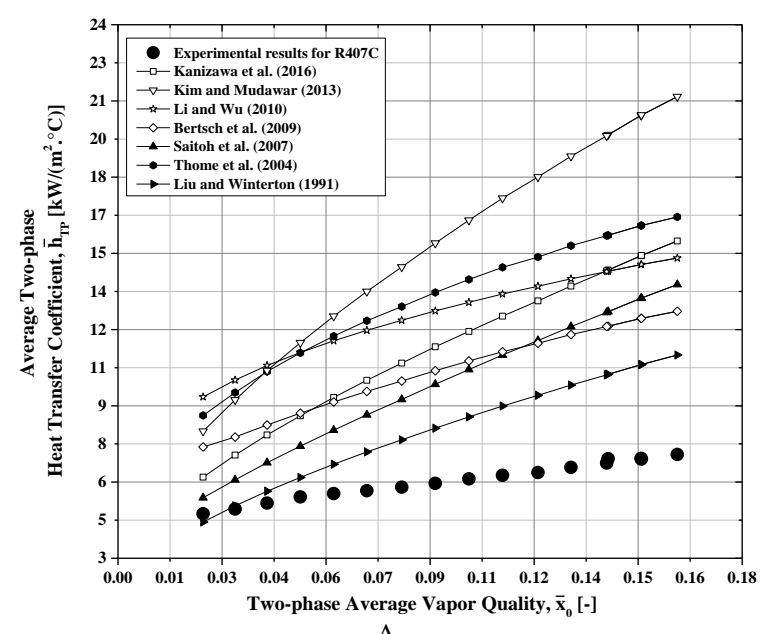

A

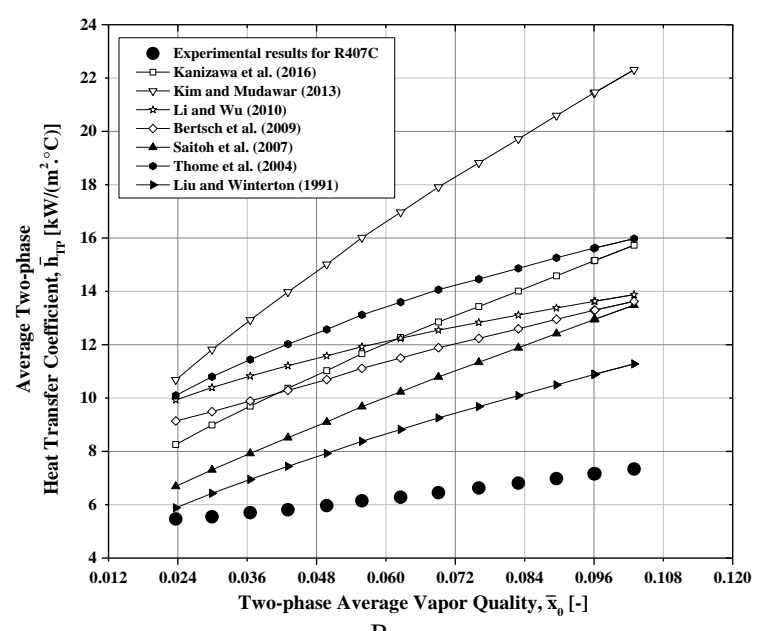

Figure 9. Comparison of the trends of $\overline{\mathrm{h}}_{\mathrm{Tp}}$ with varying $\overline{\mathrm{x}}_{0}$ according to the experimental results and the predictive methods from literature for R407C, liquid subcooling of $5^{\circ} \mathrm{C}$ and mass velocities of (A) $328 \mathrm{~kg} /\left(\mathrm{m}^{2} . \mathrm{s}\right)$ and (B) $492 \mathrm{~kg} /\left(\mathrm{m}^{2} . \mathrm{s}\right)$. 


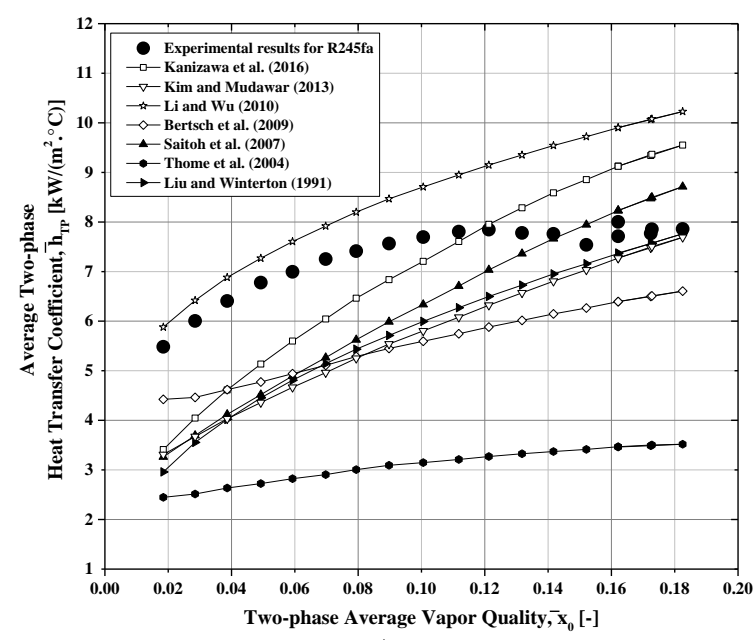

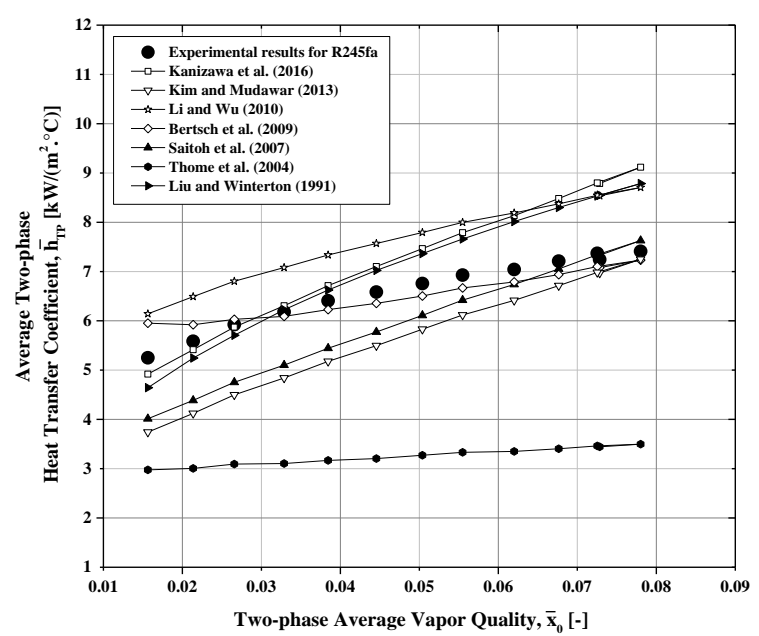

Figure 10. Comparison of the trends of $\overline{\mathrm{h}}_{\mathrm{Tp}}$ with varying $\overline{\mathrm{x}}_{0}$ according to the experimental results and the predictive methods from literature for R245fa, liquid subcooling of $5^{\circ} \mathrm{C}$ and mass velocity of (A) $328 \mathrm{~kg} /\left(\mathrm{m}^{2} . \mathrm{s}\right)$ and (B) $656 \mathrm{~kg} /\left(\mathrm{m}^{2} . \mathrm{s}\right)$.

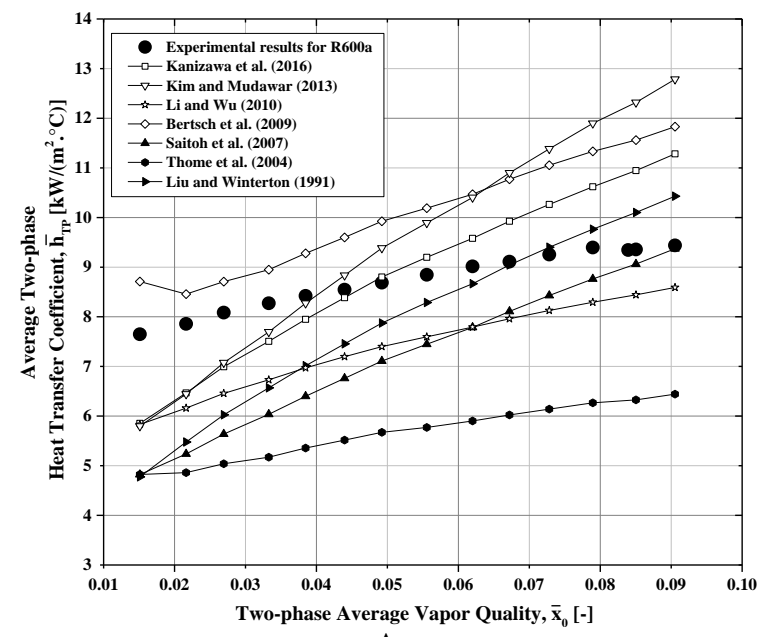

A



B

Figure 11. Comparison of the trends of $\overline{\mathrm{h}}_{\mathrm{TP}}$ with varying $\overline{\mathrm{x}}_{0}$ according to the experimental results and the predictive methods from literature for R600a, liquid subcooling of $5^{\circ} \mathrm{C}$ and mass velocity of (A) $328 \mathrm{~kg} /\left(\mathrm{m}^{2} . \mathrm{s}\right)$ and (B) $492 \mathrm{~kg} /\left(\mathrm{m}^{2} . \mathrm{s}\right)$.

\section{CONCLUSIONS}

New heat transfer data were obtained for R600a in a microchannels based heat spreader. Average effective heat transfer coefficients for flow boiling up to $10 \mathrm{~kW} / \mathrm{m}^{2}{ }^{\circ} \mathrm{C}$ were observed. The experimental data were analyzed and the main heat transfer trends were discussed. An excess of superheating was found necessary to trigger the boiling process (onset of nucleate boiling) along the microchannels. The fluid $\mathrm{R} 407 \mathrm{C}$ needed the lowest excess of superheating for the ONB followed by R134a, R600a and R245fa. The refrigerant R600a needed an excess of superheating of $12.4{ }^{\circ} \mathrm{C}$ corresponding a value 3.3 times higher than R134a. The Kandlikar et al. (2006) method provided reasonable prediction of the ONB. Under the presence of flow boiling mechanism along the microchannels, the average effective heat transfer coefficient increases with increasing the mass velocity and the liquid subcooling. Under flow boiling conditions and a fixed value of $\bar{x}$, the refrigerant R600a provided the highest average effective heat transfer coefficient. The methods of Liu and Winterton (1991), Saitoh et al. (2007), Bertsch et al. (2009) provided satisfactory predictions of the data for the refrigerants R134a, R245fa and R600a. No one of the evaluated methods provided accurate predictions of the experimental results for R407C. The method of $\mathrm{Li}$ and $\mathrm{Wu}$ (2010) provided the best prediction of the data for R245fa and R600a, predicting more than $97 \%$ of the data within an error band of $\pm 30 \%$ and giving a mean absolute error lower than $14 \%$. Finally, despite of its higher excess of superheating for the ONB, it can be concluded based on the results described in the present study, that the refrigerant R600a presents a reasonable potential to be used in heat sinks based on flow boiling through microchannels due to its low saturation pressure, good heat transfer performance, almost negligible refrigerant charge, and low global warming and 
ozone depletion potentials.

\section{ACKNOWLEDGEMENTS}

The authors gratefully acknowledge the scholarships to the second authors given by $\mathrm{CNPq}$. The financial supports under contract numbers 303852/2013-5 given by CNPq and 2011/50176-2 by FAPESP (The State of São Paulo Research Foundation, Brazil) are also appreciated and recognized.

\section{REFERENCES}

Abernethy, R. B., and Thompson, J. W., 1973, Handbook Uncertainty in Gas Turbine Measurements, Center, Arnold Engineering Development, Tennessee.

Agostini, B., Fabbri, M., Park, J. E., Wojtan, L., Thome, J. R., and Michel, B., 2007, State of the Art of High Heat Flux Cooling Technologies, Heat Transfer Engineering, Vol. 28, pp. 258-281.

Agostini, B., and Thome, J. R., 2005, Comparison of an Extended Database of Flow Boiling Heat Transfer Coefficients in MultiMicrochannel Elements with the Three-Zone Model, in: ECI International Conference on Heat Transfer and Fluid Flow in Microscale, Castelvecchio Pascoli, Italy, pp. 25-30.

Awad, M. M., and Muzychka, Y. S., 2008, Effective Property Models for Homogeneous TwoPhase Flows, Experimental Thermal and Fluid Science, Vol. 33, pp. 106-113.

Bergles, A. E., and Rohsenow, W. M., 1964, The Determination of Forced-Convection SurfaceBoiling Heat Transfer, Journal of Heat Transfer, Vol. 86, pp. 365-372.

Bertsch, S. S., Groll, E. A., and Garimella, S. V., 2009, A Composite Heat Transfer Correlation for Saturated Flow Boiling in Small Channels, International Journal of Heat and Mass Transfer, Vol. 52, pp. 2110-2118.

Bertsch, S. S., Groll, E. A., and Garimella, S. V., 2008, Refrigerant Flow Boiling Heat Transfer in Parallel Microchannels as a Function of Local Vapor Quality, International Journal of Heat and Mass Transfer, Vol. 51, pp. 4775-4787.

Chávez, C. A., Leão, H. L. S. L., and Ribatski, G., 2014, A Critical Review on Thermal Instabilities in Multi-Microchannels Heat Sinks Due to Confined Bubble Growth, in: 15th Brazilian Congress of Thermal Sciences and Engineering, Belém, Brasil.

Chen, J. C., 1966, Correlation for Boiling Heat Transfer to Saturated Fluids in Convective Flow, Industrial \& Engineering Chemistry Process Design and Development, Vol. 5, pp. 322-329.

Chen, T., and Garimella, S. V., 2006, Measurements and High-Speed Visualizations of Flow Boiling of a Dielectric Fluid in a Silicon Microchannel Heat Sink, International Journal of
Multiphase Flow, Vol. 32, pp. 957-971.

Chen, Y., Groll, M., Mertz, R., and Kulenovic, R., 2005, Pool Boiling Heat Transfer of Propane, Isobutane and their Mixtures on Enhanced Tubes with Reentrant Channels, International Journal of Heat and Mass Transfer, Vol. 48, pp. 2310-2322.

Cioncolini, A., and Thome, J. R., 2011, Algebraic Turbulence Modeling in Adiabatic and Evaporating Annular Two-Phase flow, International Journal of Heat and Fluid Flow, Vol. 32, pp. 805-817.

Colgan, E. G., Furman, B., Gaynes, M., Graham, W. S., LaBianca, N. C., Magerlein, J. H., Polastre, R. J., Rothwell, M. B., Bezama, R. J., Choudhary, R., Marston, K. C., Toy, H., Wakil, J., Zitz, J. A., and Schmidt, R. R., 2007, A Practical Implementation of Silicon Microchannel Coolers for High Power Chips, IEEE Transactions on Components and Packaging Technologies, Vol. 30, pp. 218-225.

Collier, J. G., and Thome, J. R., 1994, Convective Boiling and Condensation, Clarendon Press.

Cooper, M. G., 1984, Heat Flow Rates in Saturated Nucleate Pool Boiling-A Wide-Ranging Examination Using Reduced Properties, Advances in Heat Transfer, Vol. 16, pp. 157-239.

Costa-Patry, E., Olivier, J., Michel, B., and Thome, J. R., 2011, Two-Phase Flow Refrigerants in $85 \mu \mathrm{m}$-wide Multi-Microchannels: Part II - Heat Transfer with 35 Local Heaters, International Journal of Heat and Fluid Flow, Vol. 32, pp. 464-476.

Costa-Patry, E., Olivier, J., and Thome, J. R., 2012, Heat Transfer Charcacteristics in a Copper Micro-Evaporator and Flow Pattern-Based Prediction Method for Flowboiling in Microchannels, Frontiers in Heat and Mass Transfer, Vol. 3, pp. 013002.

Daniels, B. J., Liburdy, J. A., and Pence, D. V., 2011, Experimental Studies of Adiabatic Flow Boiling in Fractal-Like Branching Microchannels, Experimental Thermal Fluid Science, Vol. 35, pp. 110.

Davis, E. J., and Anderson, G. H., 1966, The Incipience of Nucleate Boiling in Forced Convection Flow, AIChE Journal, Vol. 12, pp. 774-780.

Dittus, F. W., and Boelter, L. M. K., 1985, Heat Transfer in Automobile Radiators of the Tubular Type, International Communications in Heat and Mass Transfer, Vol. 12, pp. 3-22.

do Nascimento, F. J., Leão, H. L. S. L., and Ribatski, G., 2013, An Experimental Study on Flow Boiling Heat Transfer of R134a in a Microchannelbased Heat Sink, Experimental Thermal and Fluid Science, Vol. 45, pp. 117-127.

Dupont, V., Thome, J. R., and Jacobi, A. M., 2004, Heat Transfer Model for Evaporation in Microchannels. Part II: comparison with the Database, International Journal of Heat and Mass Transfer, Vol. 47, pp. 3387-3401.

Harirchian, T., and Garimella, S. V., 2009, Effects of Channel Dimension, Heat Flux, and Mass 
Flux on Flow Boiling Regimes in Microchannels, International Journal of Multiphase Flow, Vol. 35, pp. 349-362.

Hetsroni, G., Mosyak, A., Segal, Z., and Ziskind, G., 2002, A Uniform Temperature Heat Sink for Cooling of Electronic Devices, International Journal of Heat and Mass Transfer, Vol. 45, pp. 3275-3286.

Jacobi, A. M., and Thome, J. R., 2002, Heat Transfer Model for Evaporation of Elongated Bubble Flows in Microchannels, Journal of Heat Transfer, Vol. 124, pp. 1131-1136.

Kaew-On, J., Sakamatapan, K., and Wongwises, S., 2011, Flow Boiling Heat Transfer of R134a in the Multiport Minichannel Heat Exchangers, Experimental Thermal Fluid Science, Vol. 35, pp. 364-374.

Kandlikar, S. G., Garimella, S., Li, D., Colin, S., and King, M. R., 2006, Heat Transfer and Fluid Flow in Minichannels and Microchannels, Elsevier.

Kanizawa, F. T., and Ribatski, G., 2016, Void Fraction Predictive Method Based on the Minimum Kinetic Energy, Journal of the Brazilian Society of Mechanical Sciences and Engineering, Vol. 38, pp. 209-225.

Kanizawa, F. T., Tibiriçá, C. B., and Ribatski, G., 2016, Heat Transfer During Convective Boiling Inside Microchannels, International Journal of Heat and Mass Transfer, Vol. 93, pp. 566-583.

Kew, P. A., and Cornwell, K., 1997, Correlations for the Prediction of Boiling Heat Transfer in Small-Diameter Channels, Applied Thermal Engineering, Vol. 17, pp. 705-715.

Kim, S. M., and Mudawar, I., 2013, Universal Approach to Predicting Saturated Flow Boiling Heat Transfer in Mini/Micro-Channels - Part II. TwoPhase Heat Transfer Coefficient, International Journal of Heat and Mass Transfer, Vol. 64, pp. 1239-1256.

Klein, S., and Alvarado, F., 2002, Engineering Equation Solver. F-Chart Software, Box.

Kutateladze, S. S., 1961, Boiling Heat Transfer, International Journal of Heat and Mass Transfer, Vol. 4, pp. 31-45.

Leão, H. L. S. L., Chávez, C. A., do Nascimento, F. J., and Ribatski, G., 2015, An Analysis of the Effect of the Footprint Orientation on the Thermal-Hydraulic Performance of a Microchannels Heat Sink During Flow Boiling of R245fa, Applied Thermal Engineering, Vol. 90, pp. 907-926.

Leão, H. L. S. L., do Nascimento, F. J., and Ribatski, G., 2014, Flow Boiling Heat Transfer of R407C in a Microchannels based Heat Spreader, Experimental Thermal Fluid Science, Vol. 59, pp. $140-151$

Levy, F. L., 1981, A Modified Maxwell-Eucken Equation for Calculating the Thermal Conductivity of Two-Component Solutions or Mixtures, International Journal of Refrigeration, Vol. 4, pp. 223-225.
Li, W., and Wu, Z., 2010, A General Correlation for Evaporative Heat Transfer in Micro/Mini-Channels, International Journal of Heat and Mass Transfer, Vol. 53, pp. 1778-1787.

Liu, Z., and Winterton, R. H. S., 1991, A General Correlation for Saturated and Subcooled Flow Boiling in Tubes and Annuli, Based on a Nucleate Pool Boiling Equation, International Journal of Heat and Mass Transfer, Vol. 34, pp. 2759-2766.

Lockhart, R. W., and Martinelli, R. C., 1949, Proposed Correlation of Data for Isothermal TwoPhase, Two-Component Flow in Pipes, Chemical Engineering Progress, Vol. 45, pp. 39-48.

Moffat, R. J., 1988, Describing the Uncertainties in Experimental Results, Experimental Thermal and Fluid Science, Vol. 1, pp. 3-17.

Ong, C. L., and Thome, J. R., 2011, Macro-toMicrochannel Transition in Two-Phase Flow: part 1 Two-Phase Flow Patterns and Film Thickness Measurements, Experimental Thermal and Fluid Science, Vol. 35, pp. 37-47.

Park, J. E., and Thome, J. R., 2010, Critical Heat Flux in Multi-Microchannel Copper Elements with Low Pressure Refrigerants, International Journal of Heat and Mass Transfer, Vol. 53, pp. 110-122.

Ribatski, G., 2013, A Critical Overview on the Recent Literature Concerning Flow Boiling and TwoPhase Flows Inside Micro-Scale Channels, Experimental Heat Transfer, Vol. 26, pp. 198-246.

Saini, M., and Webb, R. L., 2003, Heat Rejection Limits of Air Cooled Plane Fin Heat Sinks for Computer Cooling, IEEE Transactions on Components and Packaging Technologies, Vol. 26, pp. 71-79.

Saitoh, S., Daiguji, H., and Hihara, E., 2007, Correlation for Boiling Heat Transfer of R-134a in Horizontal Tubes Including Effect of Tube Diameter, International Journal of Heat and Mass Transfer, Vol. 50, pp. 5215-5225.

Schrock, V. E., and Grossman, L. M., 1962, Forced Convection Boiling in Tubes, Nuclear Science and Engineering, Vol. 12, pp. 474-481.

Sempértegui-Tapia, D. F., and Ribatski, G., 2013, An Analysis of Experimental Data and Prediction Methods for Heat Transfer Coefficient During Convective Boiling in Non-Circular MicroScale Channels, in: 8th International Conference on Multiphase Flow, Jeju, Korean.

Shah, R. K., London, A. L., Irvine, T. F., and Harnett, J. P., 1978, Laminar Flow Forced Convection in Ducts, Elsevier.

Stephan, K., and Abdelsalam, M., 1980, HeatTransfer Correlations for Natural Convection Boiling, International Journal of Heat and Mass Transfer, Vol. 23 , pp. 73-87.

Stephan, K., and Preußer, P., 1979, Wärmeübergang und maximale Wärmestromdichte Beim Behältersieden Binärer und Ternärer Flüssigkeitsgemische, Chemie Ingenieur Technik, Vol. 51, pp. 37. (in German) 
Szczukiewicz, S., Borhani, N., and Thome, J. R., 2013a, Two-Phase Heat Transfer and High-Speed Visualization of Refrigerant Flows in 100x100 $\mu \mathrm{m}^{2}$ Silicon Multi-Microchannels, International Journal of Refrigeration, Vol. 36, pp. 402-413.

Szczukiewicz, S., Borhani, N., and Thome, J. R., 2013b, Two-Phase Flow Operational Maps for Multi-Microchannel Evaporators, International Journal of Heat and Fluid Flow, Vol. 42, pp. 176-189.

Szczukiewicz, S., Borhani, N., Thome, J. R., 2013c, Fine-Resolution Two-Phase Flow Heat Transfer Coefficient Measurements of Refrigerants in Multi-Microchannel Evaporators, International Journal of Heat and Mass Transfer, Vol. 67, pp. 913929.

Szczukiewicz, S., Magnini, M., and Thome, J. R., 2014, Proposed Models, Ongoing Experiments, and Latest Numerical Simulations of Microchannel Two-Phase Flow Boiling, International Journal of Multiphase Flow, Vol. 59, pp. 84-101.

Thome, J. R., 1996, Boiling of New Refrigerants: a State-of-the-Art Review, International Journal of Refrigeration, Vol. 19, pp. 435-457.

Thome, J. R., Dupont, V., and Jacobi, A. M., 2004, Heat Transfer Model for Evaporation in Microchannels. Part I: Presentation of the Model, International Journal of Heat and Mass Transfer, Vol. 47, pp. 3375-3385.

Tibiriçá, C. B., and Ribatski, G., 2013, Flow Boiling in Micro-Scale Channels-Synthesized Literature Review, International Journal of Refrigeration, Vol. 36, pp. 301-324.

Tibiriçá, C. B., and Ribatski, G., 2014, Flow Patterns and Bubble Departure Fundamental Characteristics During Flow Boiling in Microscale channEls, Experimental Thermal and Fluid Science, Vol. 59, pp. 152-165.

Tuckerman, D. B., and Pease, R. F. W., 1981, High-Performance Heat Sinking for VLSI, IEEE Electron Device Letters, Vol. 2, pp. 126-129.

Vakili-Farahani, F., Agostini, B., and Thome, J. R., 2013, Experimental Study on Flow Boiling Heat Transfer of Multiport Tubes with R245fa and R1234ze(E), International Journal of Refrigeration, Vol. 36, pp. 335-352.

Wang, G., Cheng, P., and Bergles, A. E., 2008, Effects of Inlet/Outlet Configurations on Flow Boiling Instability in Parallel Microchannels, International Journal of Heat and Mass Transfer, Vol. 51, pp. 2267-2281.

Xu, J., Shen, S., Gan, Y., Li, Y., Zhang, W., and Su, Q., 2005, Transient Flow Pattern Based Microscale Boiling Heat Transfer Mechanisms, Journal of Micromechanics and Microengineering, Vol. 15, pp. 1344-1361.

Zhang, H. Y., 2005, Flow Boiling Heat Transfer in Microchannel Heat Sinks of Different Flow Orientations, in: Proceedings of the ASME Summer Heat Transfer Conference.

Zhang, H. Y., Pinjala, D., and Wong, T. N.,
2005, Experimental Characterization of Flow Boiling Heat Transfer in Microchannel Heat Sinks with Different Flow Orientations, in: IEEE-Electronics Packaging Technology Conference. 